Revue des patrimoines

$20 \mid 2013$

Les patrimoines de la traite négrière et de l'esclavage

\title{
Hôtel de Nointel. Watteau-Audran : sous le signe de Momus
}

\section{Christelle Inizan}

\section{(2) OpenEdition}

\section{Journals}

Édition électronique

URL : http://journals.openedition.org/insitu/10193

DOI : 10.4000/insitu.10193

ISSN : 1630-7305

Éditeur

Ministère de la Culture

Référence électronique

Christelle Inizan, « Hôtel de Nointel. Watteau-Audran : sous le signe de Momus », In Situ [En ligne], 20 | 2013, mis en ligne le 20 février 2013, consulté le 14 novembre 2019. URL : http:// journals.openedition.org/insitu/10193; DOI : 10.4000/insitu.10193

Ce document a été généré automatiquement le 14 novembre 2019.

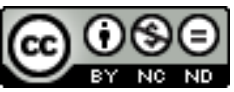

In Situ Revues des patrimoines est mis à disposition selon les termes de la licence Creative Commons Attribution - Pas d'Utilisation Commerciale - Pas de Modification 4.0 International. 


\section{Hôtel de Nointel. Watteau-Audran : sous le signe de Momus}

Christelle Inizan

\section{Essai de reconstitution du décor peint mural}

1 L'examen approfondi des plafonds à décor de singeries peints par Antoine Watteau n'en finit pas d'éclairer d'un jour nouveau l'iconographie et la symbolique de l'époque Régence à Paris. 
Figure 1

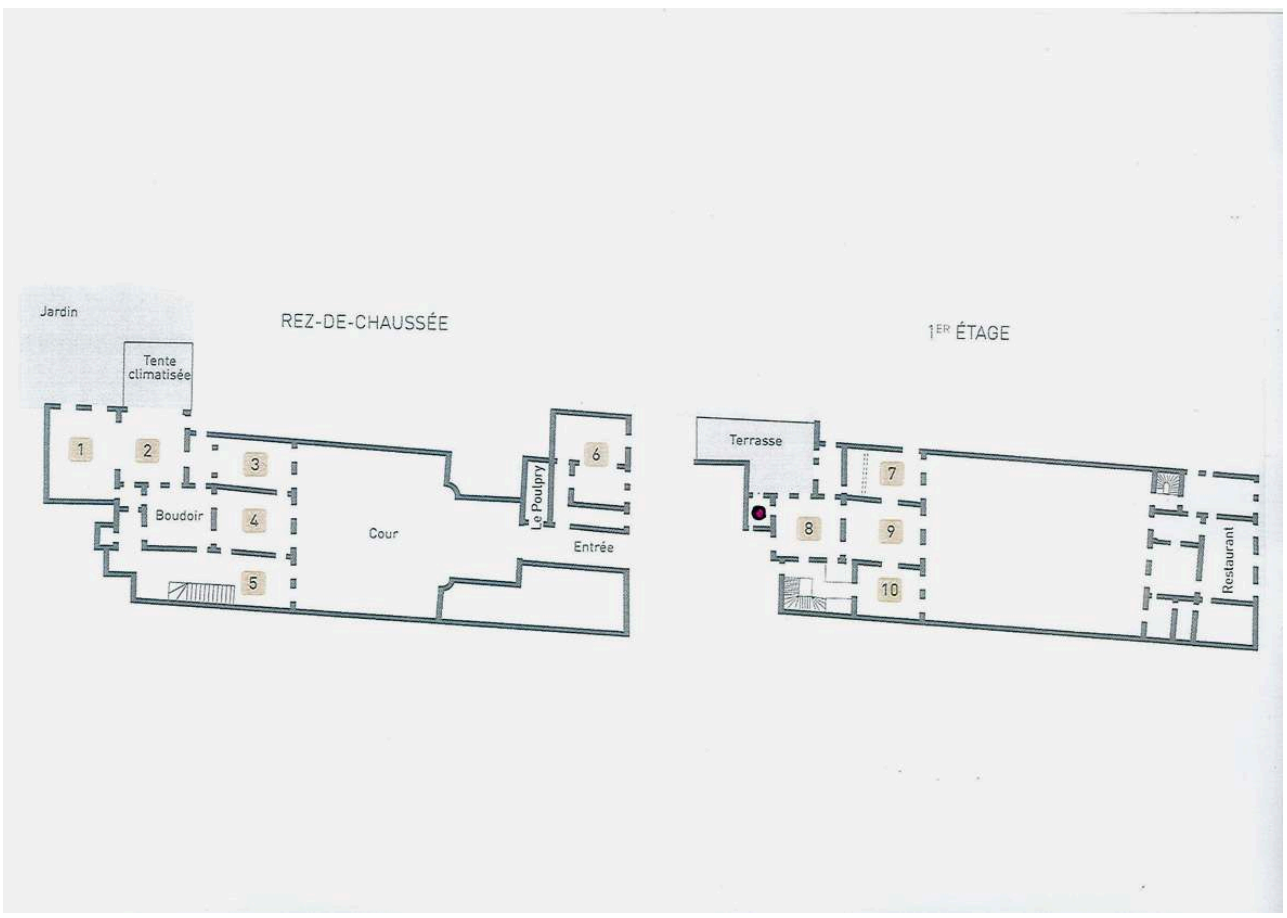

Plan de situation des salons de l'actuelle Maison des Polytechniciens, ancien hôtel de Nointel. Premier étage. Cabinet Watteau signalé par le point rouge.

Phot. Inizan, Christelle. (c) CRMH île-de-France, 2011.

Dans le n 16 d'In Situ, revue des patrimoines l'étude d'un plafond peint en 1713 situé dans la maison du 26 rue de Condé nous avait conduit à faire la comparaison avec celui d'un cabinet de l'ancien hôtel particulier de Louis Béchameil, marquis de Nointel ${ }^{12}$, sis 12 rue de Poitiers à Paris $7^{e}$ (fig. $\mathbf{n}^{\circ} \mathbf{1}$ ), autre décor aux singes, résultant lui aussi d'une collaboration entre Claude III Audran (1658-1734) ${ }^{3}$ et Antoine Watteau (1684-1721) (fig. $\mathbf{n}^{\circ} \mathbf{2}$ ). Faute d'avoir pu officiellement protéger le premier plafond, le second, grâce à la bienveillance de son propriétaire, la Maison des Polytechniciens, vient d'être classé au titre des Monuments historiques. 
Figure 2

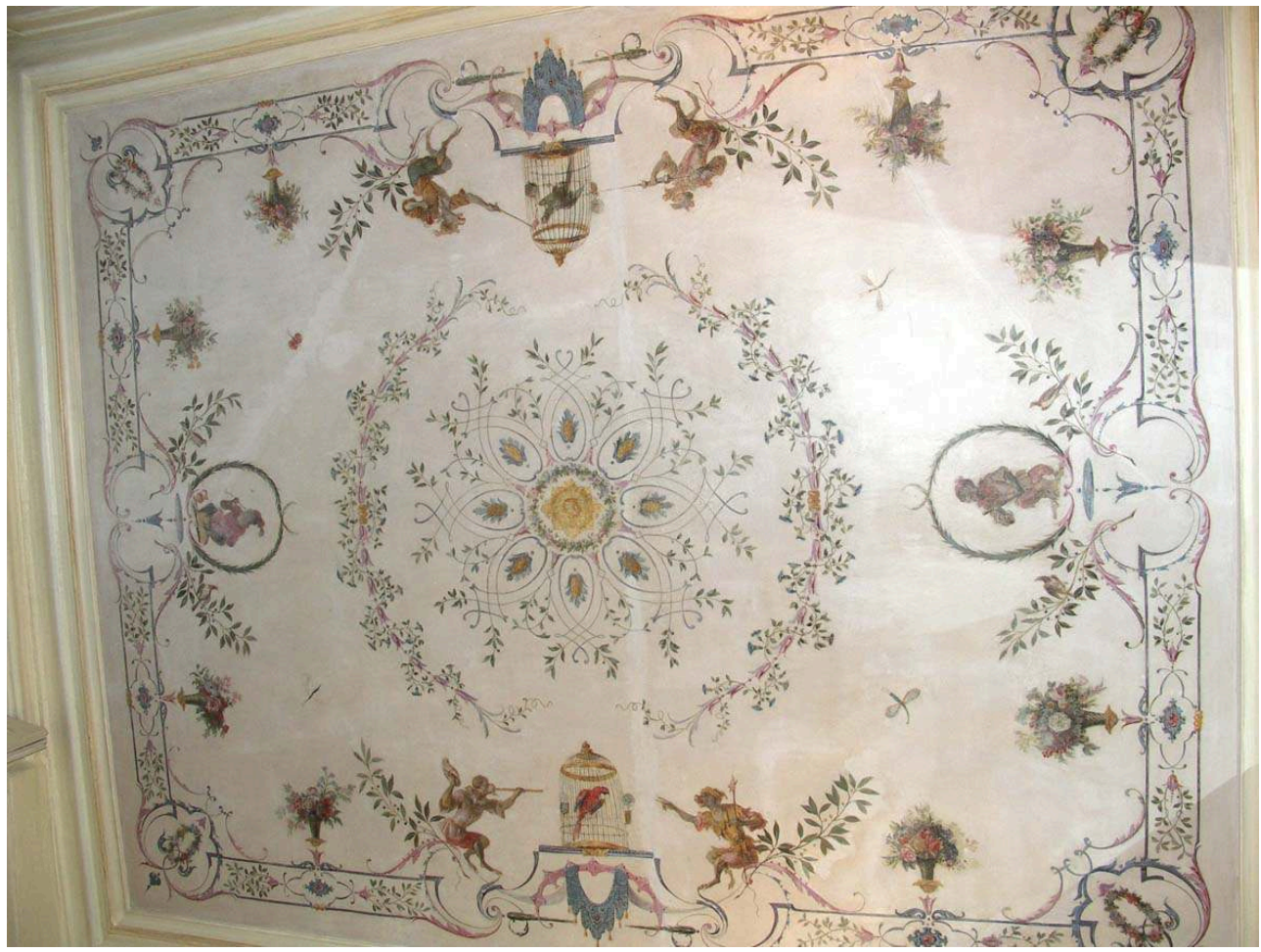

Plafond aux singes de l'hôtel de Nointel, 12 rue de Poitiers à Paris.

Phot. Inizan, Christelle. (c) CRMH Île-de-France, 2010.

En nous remettant à l'ouvrage et en tentant de compléter le décor plafonnier actuel (d'environ 3,40 x $3 \mathrm{~m}$ ) peint sur plâtre, en replaçant les panneaux muraux du petit cabinet (fig. $\left.\mathbf{n}^{\circ} \mathbf{3}\right)\left(\right.$ fig. $\left.\mathbf{n}^{\circ} 4\right)$ réalisés par Watteau ${ }^{5}$ - panneaux peints dispersés ou simplement connus par des gravures éditées par Pierre Louis Surugue (1710-1772) et Edmé-François Gersaint (1694-1750) ${ }^{6}$ (fig. $\mathbf{n}^{\circ}$ 5), nous avons pu mettre en évidence la cohérence du programme iconographique qui présidait autrefois au décor de cette pièce. 
Figure 3

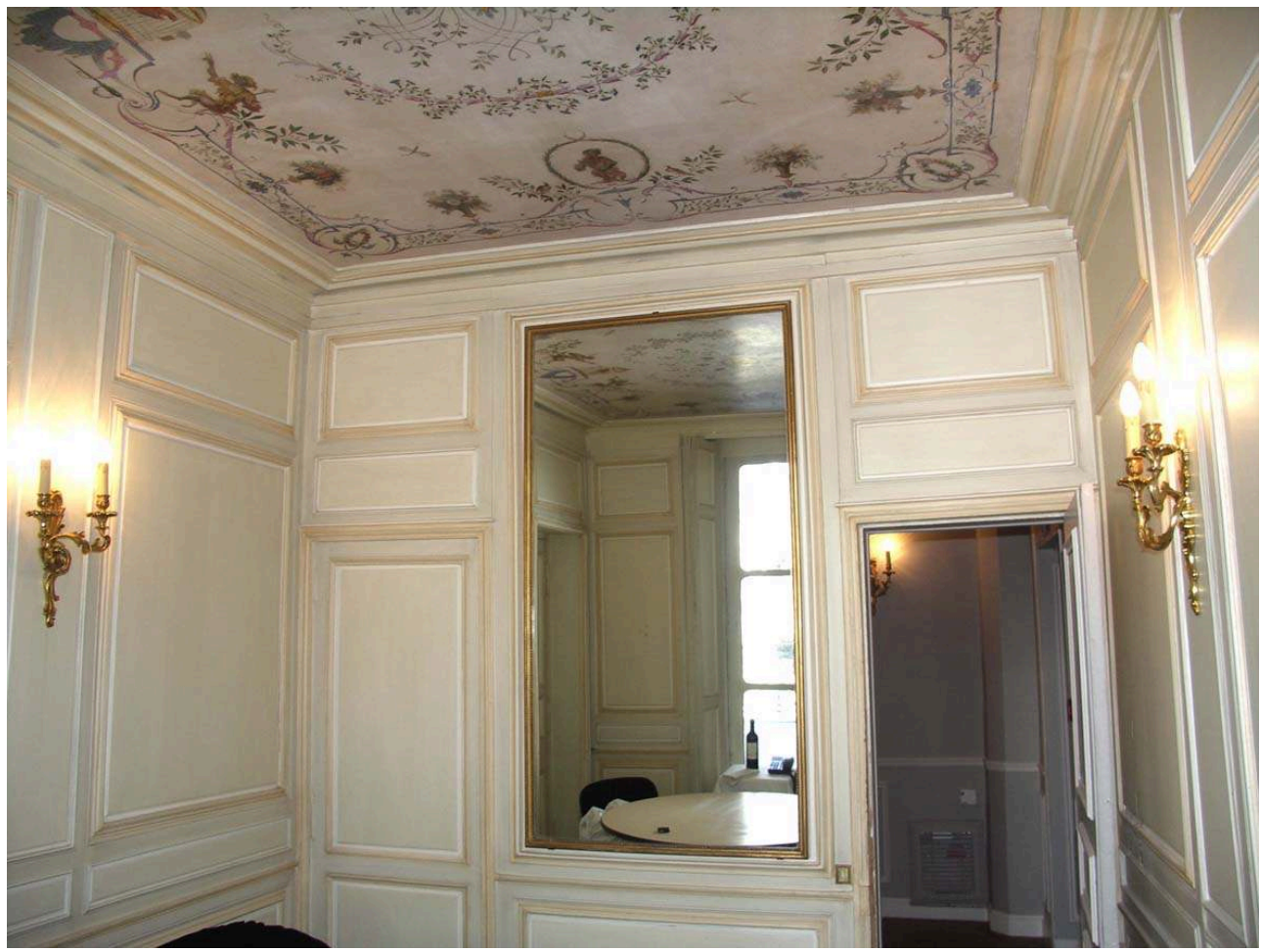

Hôtel de Nointel, cabinet peint par Antoine Watteau et Claude III Audran, côté corridor. Phot. Inizan, Christelle. (c) CRMH Île-de-France, 2010.

Figure 4

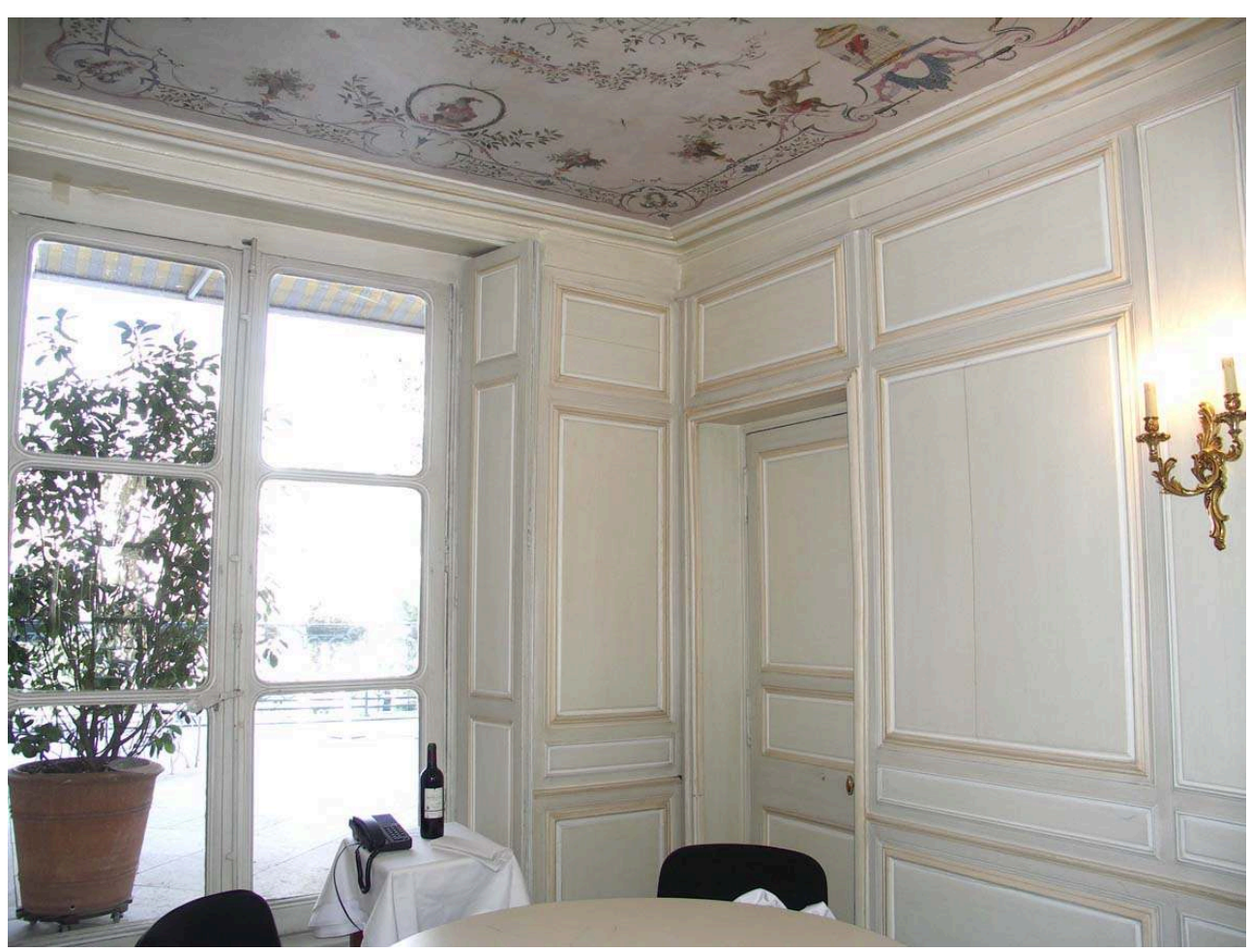

Hôtel de Nointel, cabinet peint par Antoine Watteau et Claude III Audran, côté fenêtre sur jardin. Phot. Inizan, Christelle. (C) CRMH Île-de-France, 2010. 
Figure 5
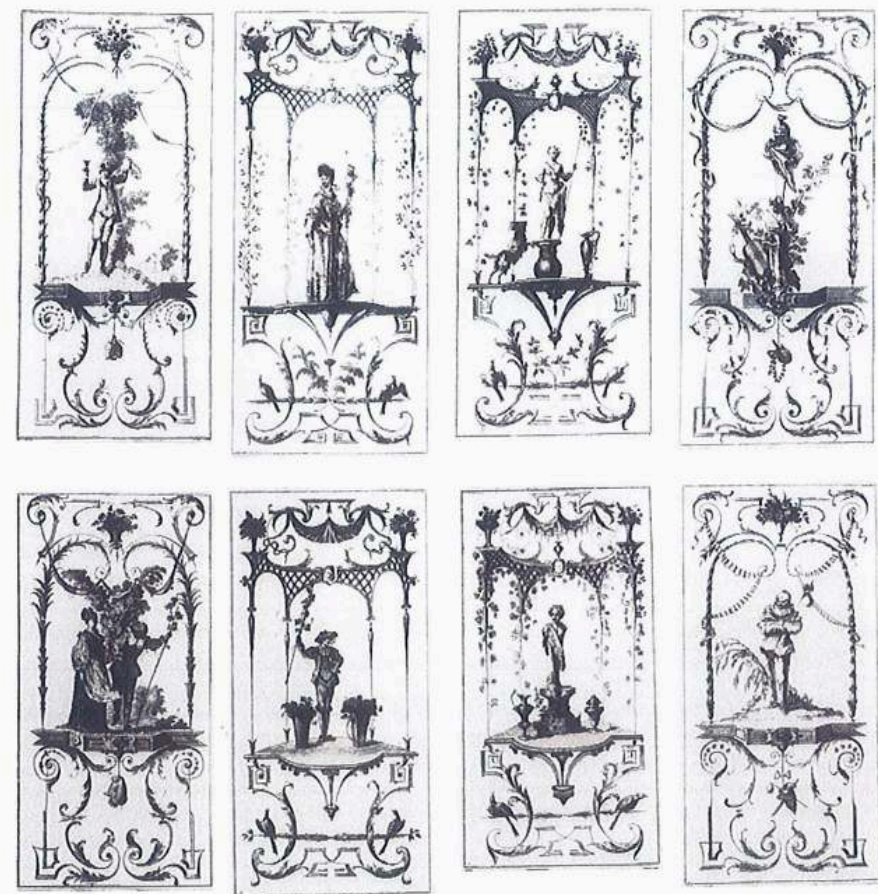

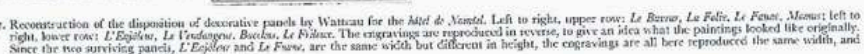

Proposition de reconstitution du décor de lambris peints du cabinet de l'hôtel de Nointel à partir des huit gravures connues d'Antoine Watteau. Jean Cailleux "Decorations by Antoine Watteau for the Hotel de Nointel". Burlington Magazine, London, vol. CIII, n696, march 1961, advertising supplement.

(c) CRMH Île-de-France, 2012

Les deux seuls panneaux sur bois conservés, à savoir l'enjôleur et le faune, sont visibles

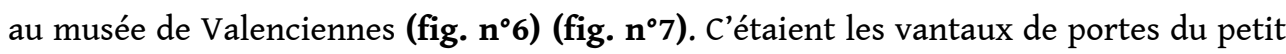
cabinet. Comme le précisait le catalogue de vente du comte de la Béraudière des 18 et 30 mai 1885, ces deux panneaux cachés sous une épaisse couche de peinture à la colle ornaient les portes du grand salon (lequel communiquait précisément avec le petit cabinet). Ils faisaient partie d'un ensemble plus conséquent d'au moins huit panneaux muraux supplémentaires parmi lesquels se trouvaient Bacchus, le vendangeur, le buveur, Momus (fig. $\mathbf{n}^{\circ} \mathbf{8}$ ), la Folie et le frileux ${ }^{7}$. Malgré la perte des lambris d'appui ${ }^{8}$ et des parecloses, nous pouvons tenter de replacer les panneaux connus en usant des principes de symétrie pour les motifs de treillages et de consoles. 
Figure 6

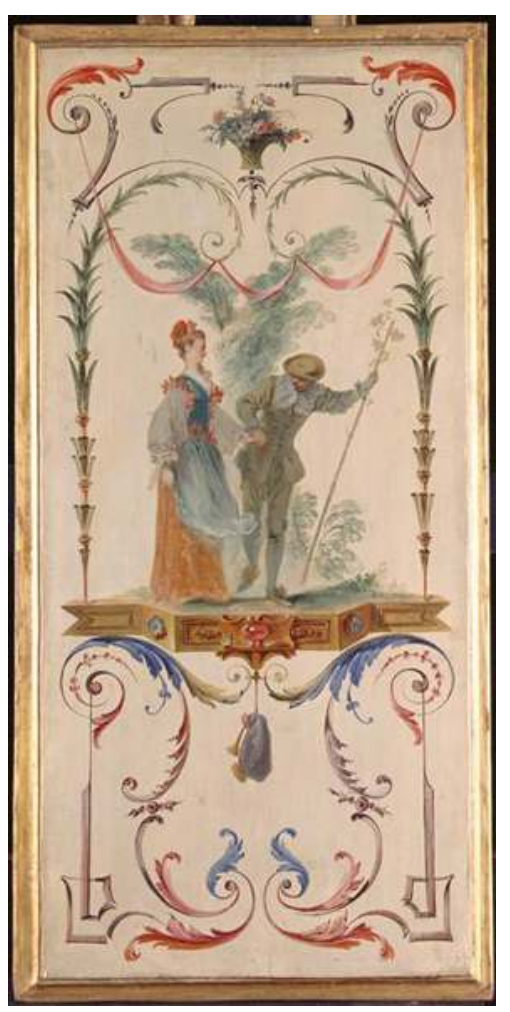

Antoine Watteau «L'enjôleur », huile sur panneau, 79,5 × $39 \mathrm{~cm}$. № inventaire 99.4.1. Valenciennes, Musée des Beaux-Arts.

(c) RMN/ Régis Decottignies. 
Figure 7

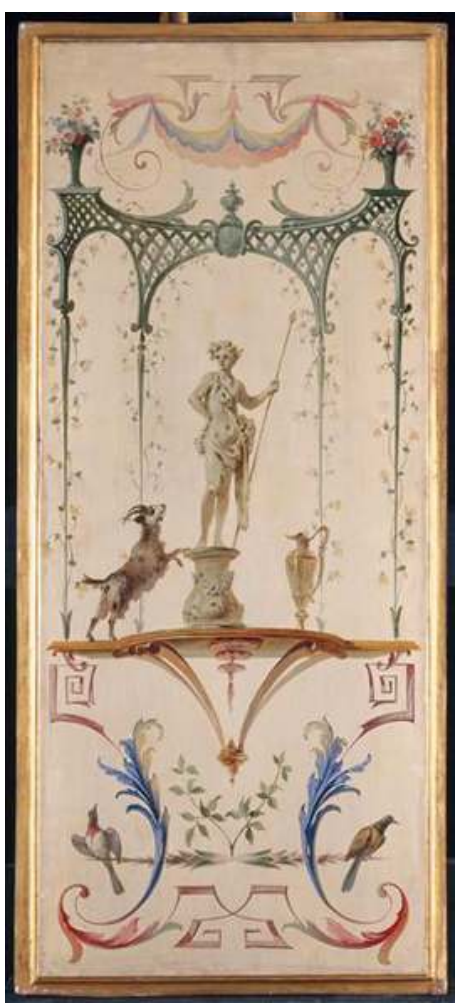

Antoine Watteau « Le faune ». Huile sur panneau, $88 \times 39 \mathrm{~cm}$. N inventaire 99.4.2. Valenciennes, Musée des Beaux-Arts.

(c) RMN/ Régis Decottignies. 


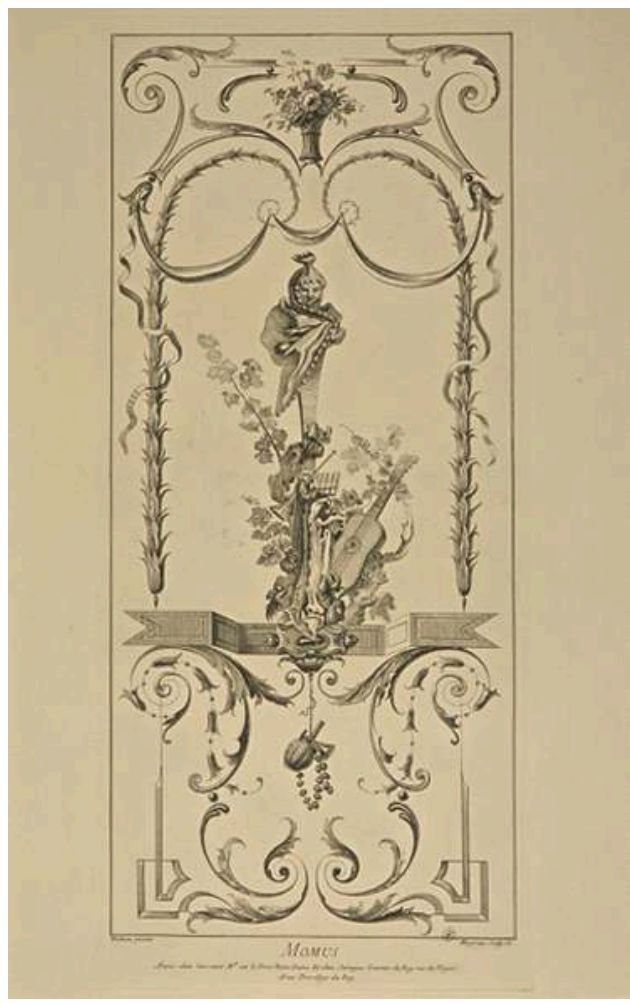

Antoine Watteau « Momus ». Eau-forte sur papier vergé gravée par Jean Moyreau en 1738 et éditée chez Surugue et chez Gersaint. 50,8 x 23,1 cm. Ninventaire E.86.1.22. Valenciennes, Musée des Beaux-Arts.

(c) RMN

Le frileux se retrouve ainsi logiquement près de la fenêtre donnant actuellement sur une terrasse. Son image se reflète, inversée, dans le miroir (lequel faisait conventionnellement face à la fenêtre donnant sur le jardin) : il observe goguenard le couple d'amoureux à sa gauche, panneau connu sous l'appellation l'enjôleur. Latéralement, se déploie le faune (vantail de la porte communiquant avec le grand salon), suivi sur les murs par le buveur, Momus et la Folie. À l'opposé, côté mur mitoyen (celui autrefois de la cheminée) ${ }^{9}:$ Bacchus, et de l'autre côté de la glace du trumeau de cheminée : le vendangeur. Ces deux panneaux présentent en effet des ornements qui esquissent des meubles de desserte qui trouvent parfaitement leur place de part et d'autre d'une cheminée.

6 Cette reconstitution met en lumière le couple central de cette composition: Momus et sa compagne la Folie qu'entourent des personnages ou des divinités bachiques.

7 Souvenons-nous que Momus, demi-dieu du panthéon grec, personnification du sarcasme et de la moquerie, fut le seul à avoir compris Bacchus et ses débordements. Momus, c'est encore le dieu porte-marotte (symbole de la division entre l'être et le paraître, entre la réalité et l'illusion), le patron de la foire (fig. $\mathbf{n}^{\circ} \mathbf{9}$ ). Sa popularité redouble au début du XVIII siècle, époque où l'on tourne résolument le dos aux grands dieux de l'olympe, repris sciemment par la pompe louis-quatorzienne, pour se tourner vers les demi-dieux plus à même d'exprimer le conflit des forces internes, le «bellum intestinum $»^{10}$. Loin de disparaître, la mythologie prend ainsi une figure riante. Elle est saisie par le prisme de la convention théatrale (où croyance et scepticisme se 
confondent) ayant pour effet une certaine " poétisation ». Antoine Watteau, on le sait, est le maître incontesté de cette mise en place d'une mythologie moderne. C'est le buste de Momus qui préside à L'amour du théâtre français, tableau conservé au Staatliche Museen de Berlin ${ }^{11}$. Au premier plan : la marotte. Au second : la Folie, reconnaissable à sa toilette jaune et verte et à son étole à grelots ${ }^{12}$. À ses côtés, Bacchus trinque avec l'homme au carquois, personnification de l'amour.

Figure 9

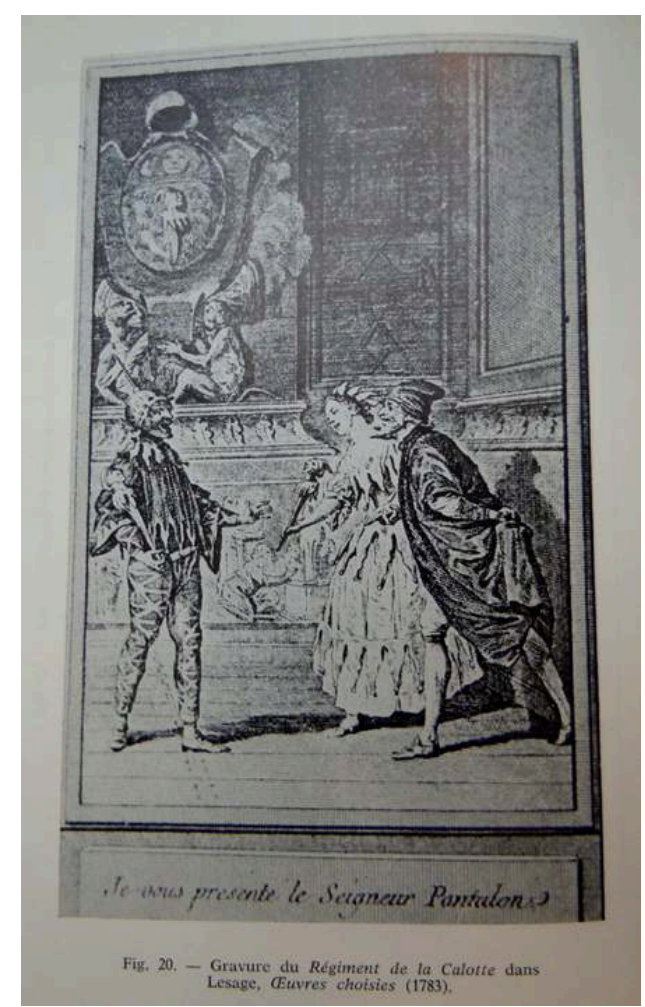

Gravure « La folie présentant à Momus le seigneur Pantalon » extraite de la publication de la pièce en un acte d'Alain René LESAGE. Le Régiment de la calotte. Livret satirique représenté à la Foire SaintLaurent le ${ }^{\text {er }}$ septembre 1721 et joué à nouveau le 2 octobre suivant au Palais Royal par ordre de Madame. BnF YF 5904.

(c) BnF.

À l'hôtel de Nointel, le thème de l'amour naissant se retrouve aussi. C'est le panneau de L'Enjôleur qui permet à l'artiste d'aborder l'éveil des sens sans tomber dans le cynisme du libertinage, peu conforme à la personnalité de Watteau ${ }^{13}$. Le peintre valenciennois avait déjà associé, dans des compositions qui se répondent, Les enfants de Momus à La cause badine ${ }^{14}$.

Voici le temps de l'aimable Régence

Temps fortuné, marqué par la licence

Où la Folie, agitant son grelot,

D’un pied léger parcourt toute la France.

Voltaire. La Pucelle, Oeuvres, XI, 213.

\section{L'iconographie du régiment de la calotte}

8 S'étant imprégné de l'esprit des murs, levons la tête. À première vue, les singeries du plafond ne semblent pas en liaison avec ce registre lambrissé, n'étaient les vases fleuris, les paires d'oiseaux perchés, les cartouches qui se répondent effectivement. Et 
pourtant... Elles forment un ensemble cohérent qui ne saurait être dissocié. Le thème bachique est repris subtilement dans la rosace centrale (pommes de pin du thyrse de Bacchus) et par le verre de vin rouge tenu par un des singes, qui, de l'autre patte, tente de faire boire un perroquet en lui tendant au bout d'un bâton une éponge imprégnée du divin breuvage. Surtout, nous sommes en présence d'une iconographie précise qui ne saurait être sujette à une interprétation approximative : celle du régiment de la calotte. Avant d'en détailler les symboles, quelques mots sur cette société satirique, bachique et carnavalesque de la première moitié du XVIII ${ }^{\mathrm{e}}$ siècle, inventée à la fin du règne de Louis XIV par quelques hommes d'esprit qui s'inspirèrent probablement de la facétieuse République de Babin, fondée en Pologne au milieu du XVI ${ }^{e}$ siècle, laquelle professait un certain idéal aristocratique ${ }^{15}$.

C'est à Antoine de Baecque ${ }^{16}$, qui a consacré plusieurs écrits au Régiment de la Calotte, que l'on doit la définition la plus précise de cette société de rieurs qui, un demi-siècle durant, allait se signaler par la verve de ses satires, exerçant « la police du ridicule » au sein de la cour et de la haute société parisienne.

L'auteur reprend le récit fondateur de cette société relaté dans l'oraison funèbre du général Aimon ${ }^{{ }^{e r 1} 1}$. Des mousquetaires, lors d'une soirée bien arrosée de 1702, décident de corriger les mœurs et les styles à la mode (l'Académie, la tragédie) par l'arme du ridicule. Ces pères fondateurs, militaires, donneront à leur société une organisation inspirée de l'armée (général en tête, grand écuyer, lieutenant-colonel, chefs de bataillon, chefs de brigade, vivandières) mais aussi ingénieur en chef, maître de musique, médecin, etc. Et même un tribunal et une milice - parfois redoutable -.

11 Le brevet, signe de reconnaissance des calottins, est un détournement satirique de la lettre patente. Il s'agit de petits textes, en vers ou prose, énumérant de manière caustique les travers et les ridicules qui distinguent telle ou telle victime. Ils sont censés ramener l'égaré à la raison.

Le régiment de la calotte, ce sont encore des rites (protocole d'intronisation, défilés et cortèges de triomphe, repas des fondateurs et des dignitaires du groupe durant les nuits de pleine lune, conciliabules bachiques ${ }^{18}$, réunions d'écriture dans des cafés) et une iconographie largement diffusée par les publications calottines (frontispices, hauts de pages et marges imagés, gravures de blason et d'étendard, portrait de général calottin) et par la distribution de médailles ${ }^{19}$. 
Figure 10

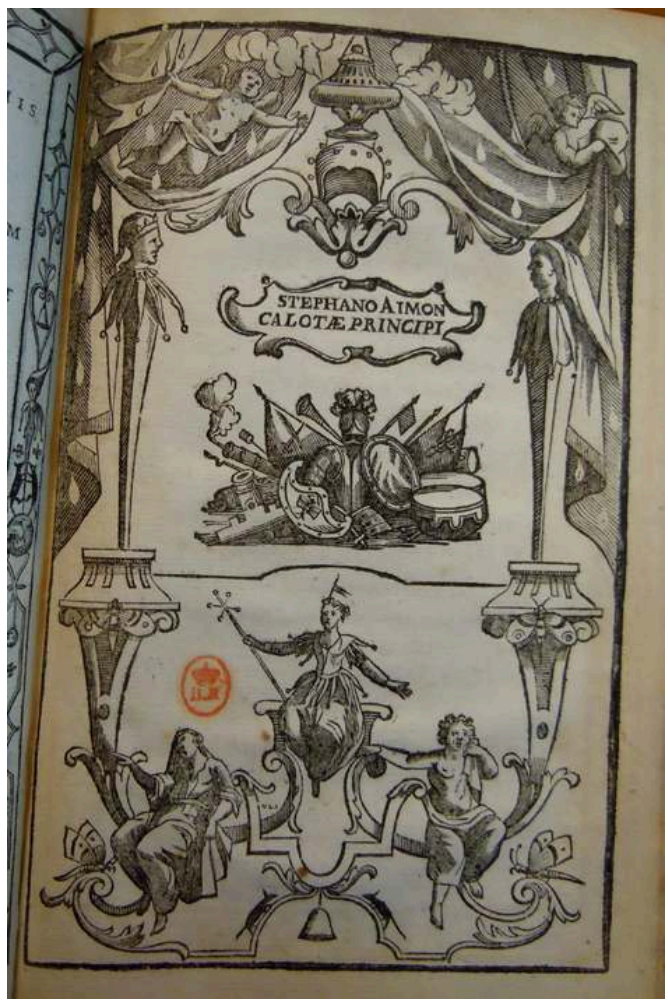

Gravure en pleine page de l'oraison funèbre du général Aimon ler. Écusson central « Stephano Aimon, calotae principi ». Illustration extraite de l'ouvrage de BOSC du BOCHET. Journée calotine en deux dialogues (an 7732 de l'ère calottine-1732). In 8º, 121 p., BnF Z 17183.

(c) BnF.

13 La marotte d'abord, c'est le sceptre des fous et des bouffons de cour (la charge du dernier fou de cour ayant été abolie par Louis XIV, les calottins se sont saisis de son attribut pour prendre la relève). La Folie agite la marotte sur le drapeau du régiment ${ }^{20}$ et sur une pleine page de l'Oraison funèbre du général Aimon Ir (fig. $\left.\mathbf{n}^{\circ} \mathbf{1 0}\right)$. Sur un avers de médaille c'est Momus qui la brandit (fig. $\mathbf{n}^{\circ} \mathbf{1 1}$ ). Le généralissime la désigne encore avec insistance sur la belle gravure signée B.A. (Benoît Audran - frère de Claude III Audran -) d'après Charles Antoine Coypel (fig. $\mathbf{n}^{\circ} \mathbf{1 2}$ ). 
Figure 11

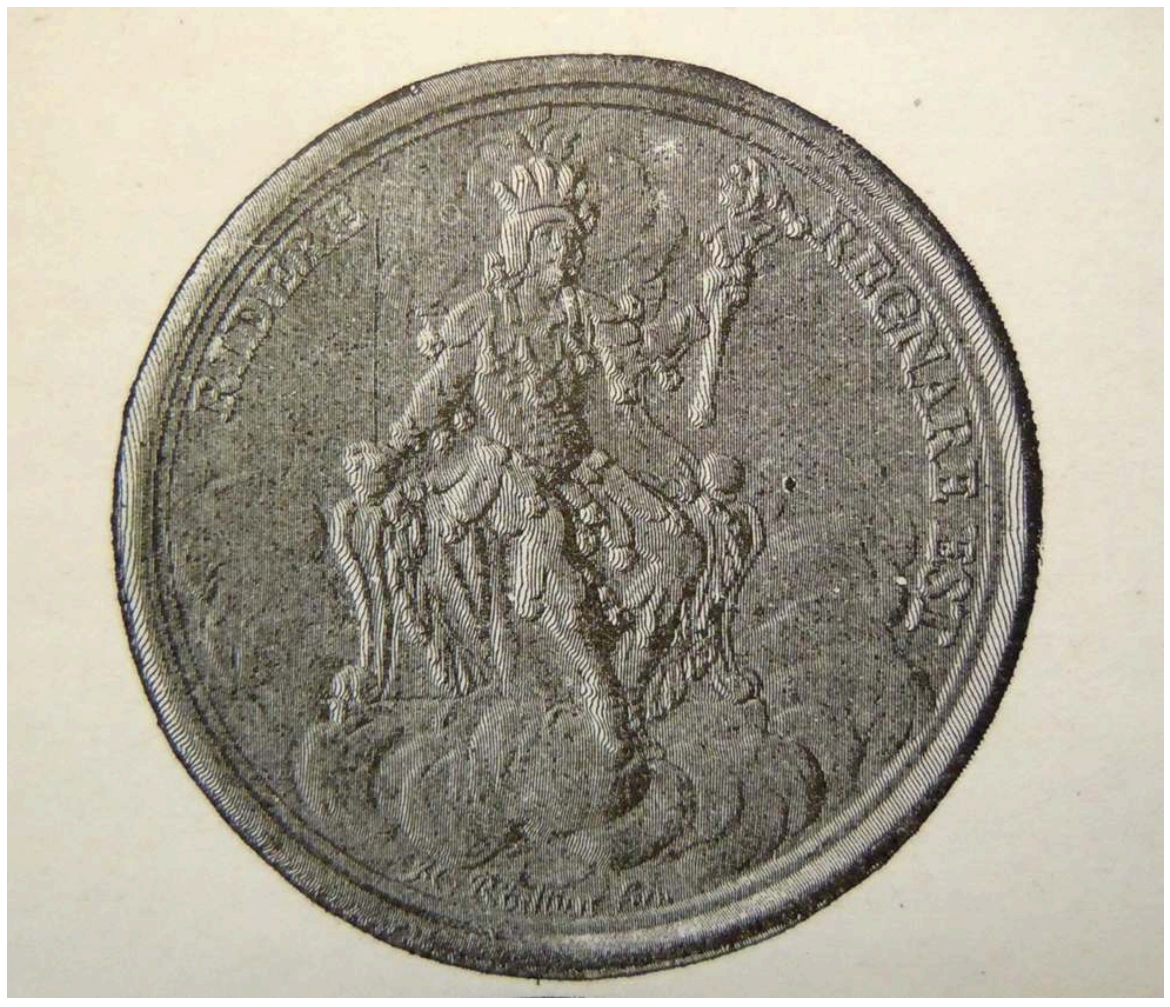

Le généralissime Aimon ler travesti en Momus. Avers de la médaille du régiment de la Calotte conservée au cabinet des médailles de la BnF et publiée dans l'ouvrage de Léon HENNET. Le régiment de la Calotte. Paris : Librairie des bibliophiles, 1886, p. 229.

(c) BnF. 
Figure 12

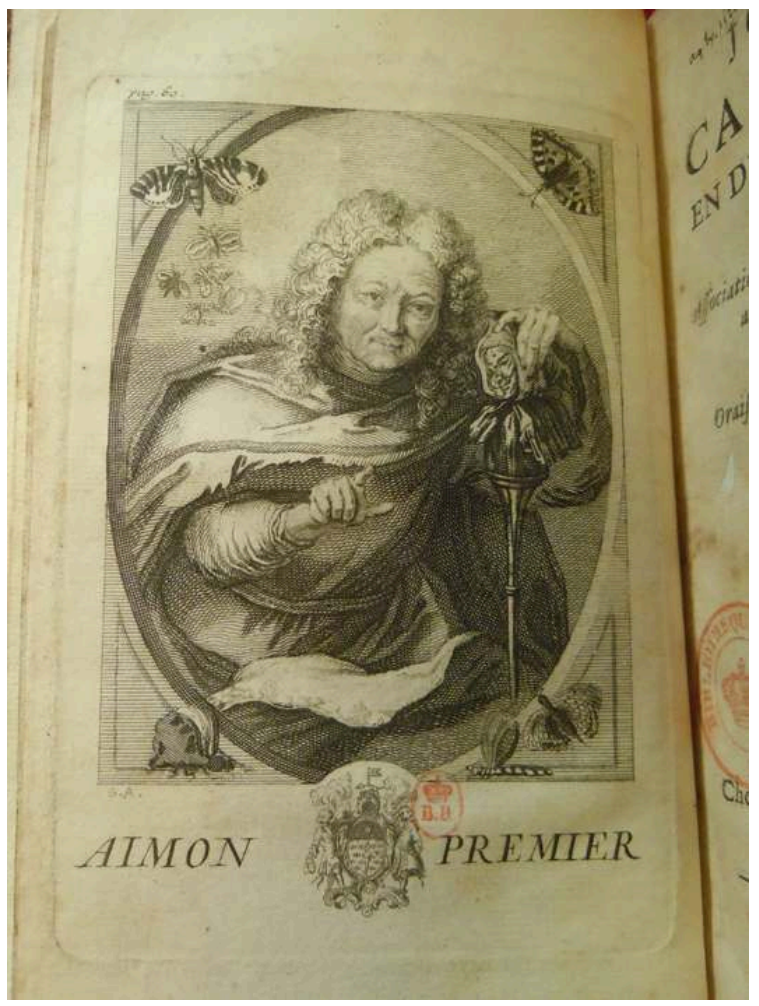

Gravure de B.A (Benoît Audran) d'après Charles Antoine Coypel représentant dans un médaillon, cerné de papillons, Aimon ler tenant une marotte et faisant le signe de reconnaissance des calottins. Blason du régiment au bas de la composition flanqué d'un singe au chapeau et d'un singe au brevet. Cornes d'abondances inversées et fumantes. Illustration extraite d'une variante de l'ouvrage de BOSC du BOUCHET. « Journée calotine en deux dialogues (an 7732 de l'ère calottine-1732) ». In 8, p. 60, BnF RES Z 17183.

(C) BnF.

Dans ce portrait, Aimon Ier semble esquisser un geste obscène, lequel se retrouve précisément sur le plafond, dans le singe à la marotte (fig. $\left.\mathbf{n}^{\circ} \mathbf{1 3}\right)$. Cette gestuelle évoque de prime abord les cornes du cocu - qui parait bien dans la veine de l'esprit calottin $^{21}$-. Pourtant, à y observer de plus près, cela ressemble plutôt à un crochet exécuté avec les deux premiers doigts, un $\mathrm{C}$, déterminant ainsi une section de la sphère (la calotte). La calotte c'est encore la protection totale de l'épée au XVII siècle. L'épée, arme par excellence des mousquetaires du roi ${ }^{22}$. 
Figure 13

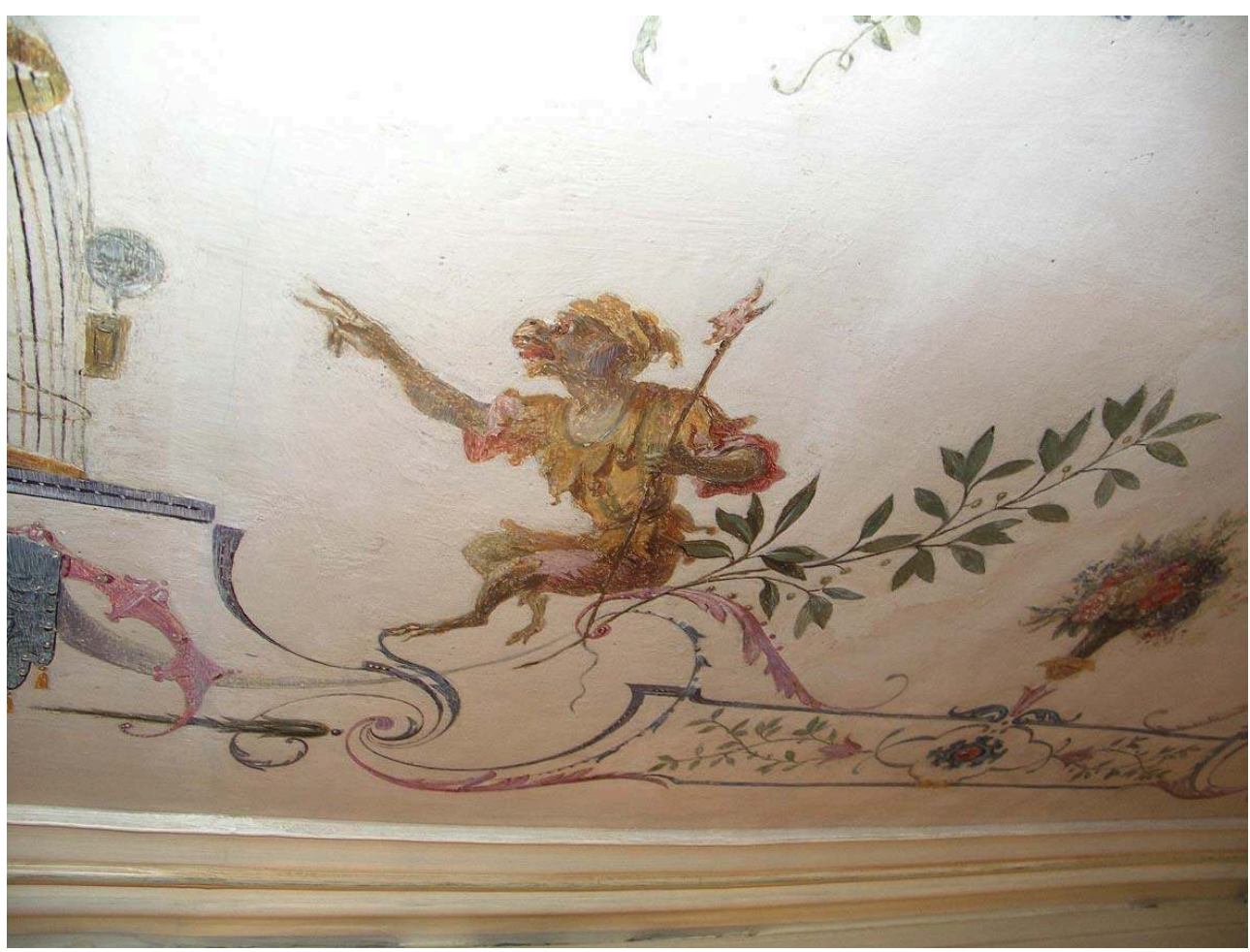

Plafond du cabinet. Antoine Watteau. Singe à la marotte.

Phot. Inizan, Christelle. (c) CRMH Île-de-France, 2010.

«Luna duce auspice Momo» (Avec la lune pour guide et sous les auspices de Momus) telle est la devise du régiment (fig. $\mathbf{n}^{\circ} \mathbf{1 4}$ ). Dans l'iconographie calottine, les croissants de lune sont affrontés de part et d'autre de l'astre ; sur notre plafond, ils sont simplement évoqués par les volutes supérieures des tresses de feuillage formant médaillons autour du singe à la bulle de savon et du singe à la lunette (fig. $\mathbf{n}^{\circ} 15$ ). 


\section{Figure 14}

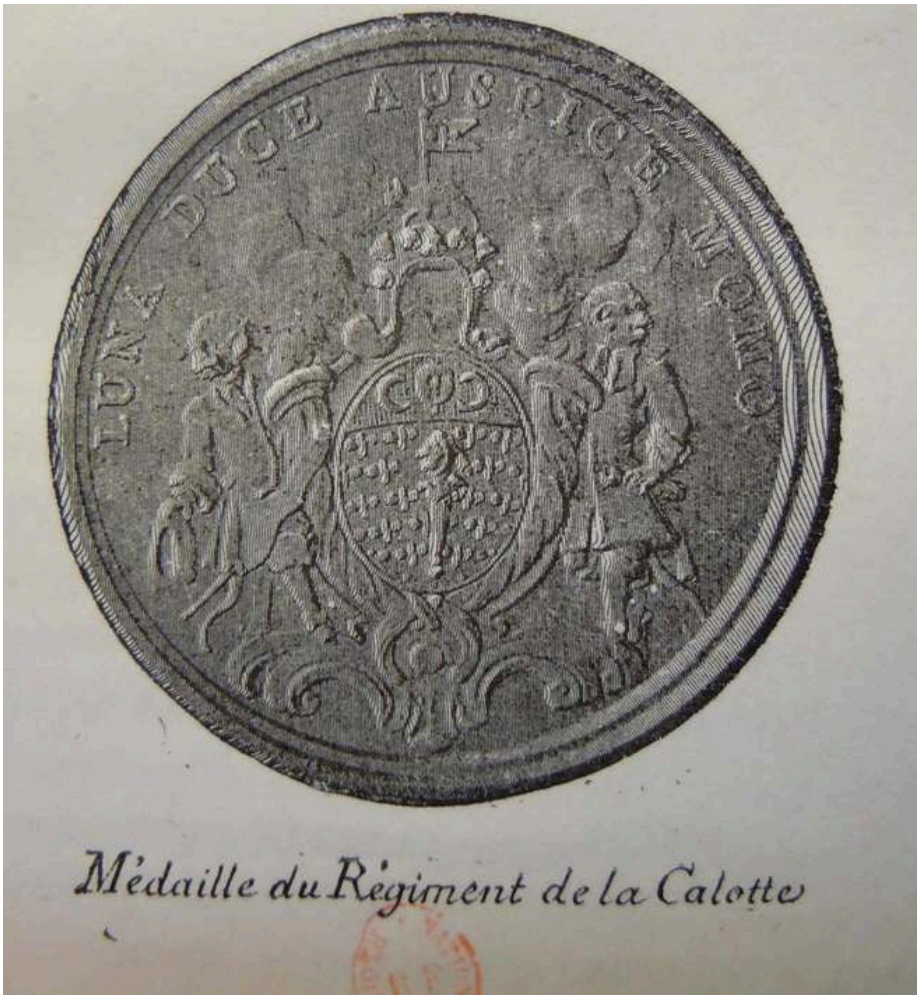

Blason et devise du Régiment de la Calotte. Revers de la médaille du régiment de la Calotte conservée au cabinet des médailles de la BnF et publiée dans l'ouvrage de Léon HENNET. Le régiment de la Calotte. Paris : Librairie des bibliophiles, 1886, p. 229.

(c) BnF. 
Figure 15

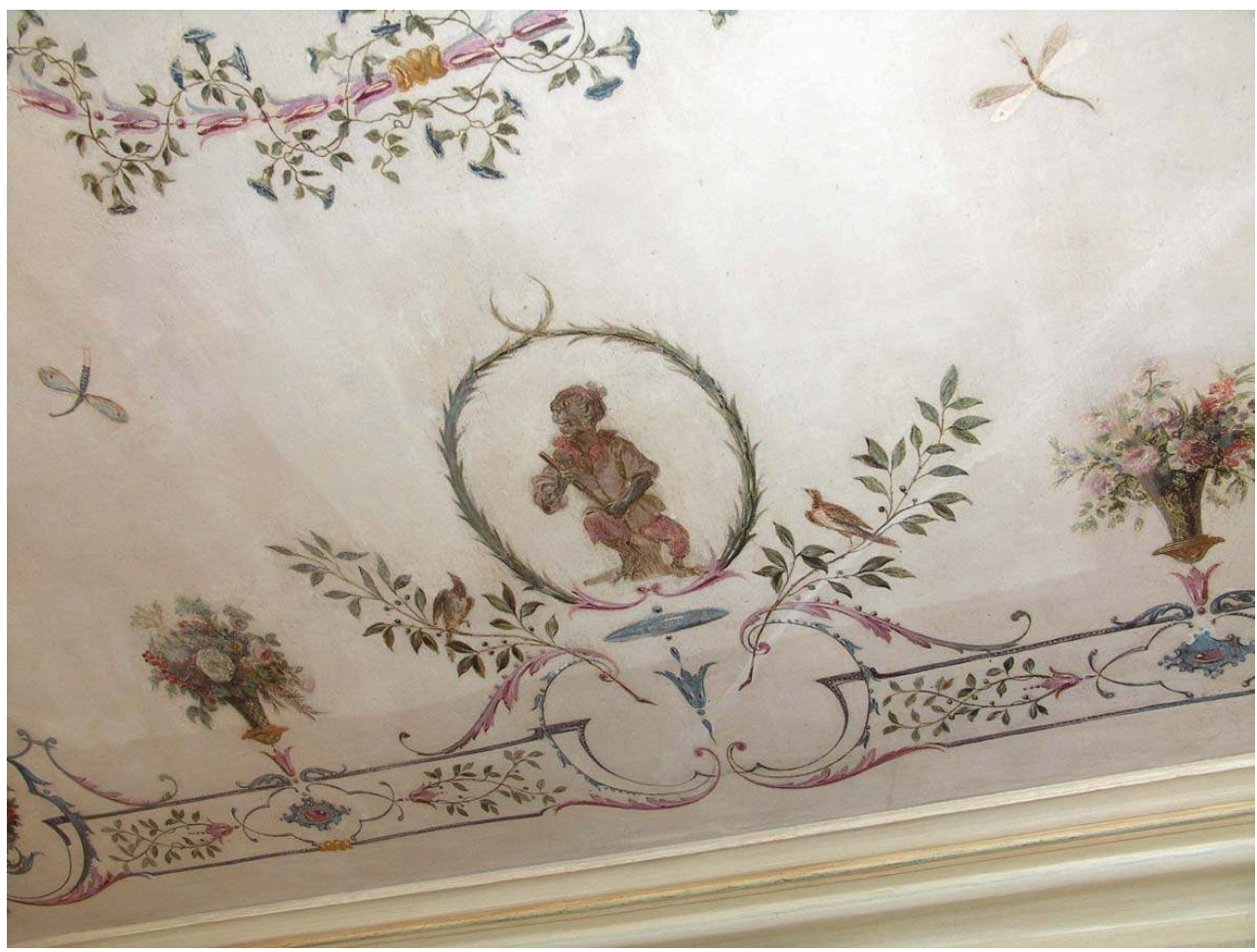

Plafond du cabinet. Antoine Watteau. Singe à la lunette astronomique.

Phot. Inizan, Christelle. (c) CRMH Île-de-France, 2010. 
Figure 16

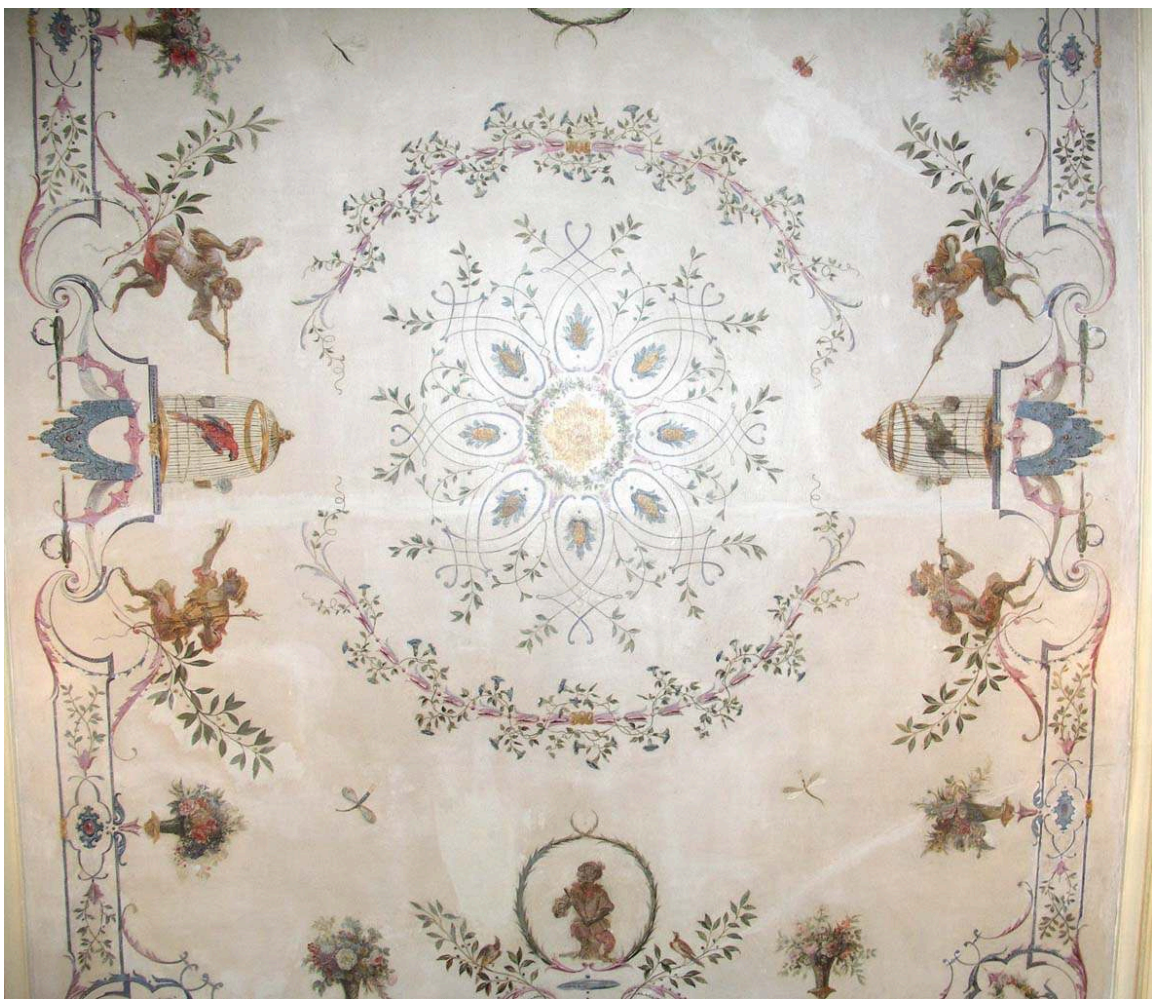

Plafond du cabinet. Détail de la composition centrale notamment des papillons de la folie, à michemin chacun de deux vases fleuris.

Phot. Inizan, Christelle. (c) CRMH Île-de-France, 2010. 


\section{Figure 17}

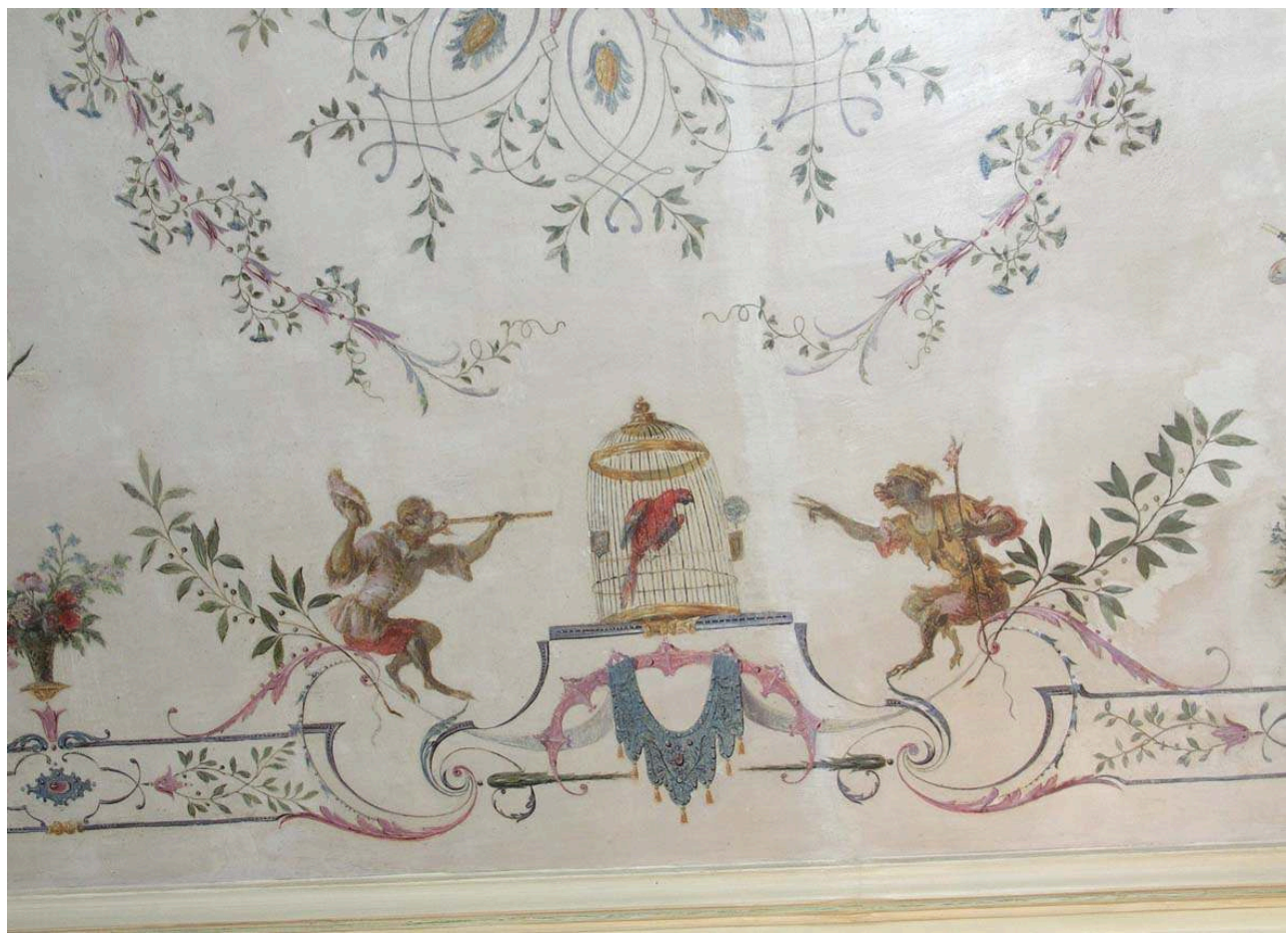

Plafond du cabinet. Singe au chapeau et à la sarbacane et singe à la marotte travesti en Momus. Phot. Inizan, Christelle. (c) CRMH île-de-France, 2010.

\section{Figure 18}

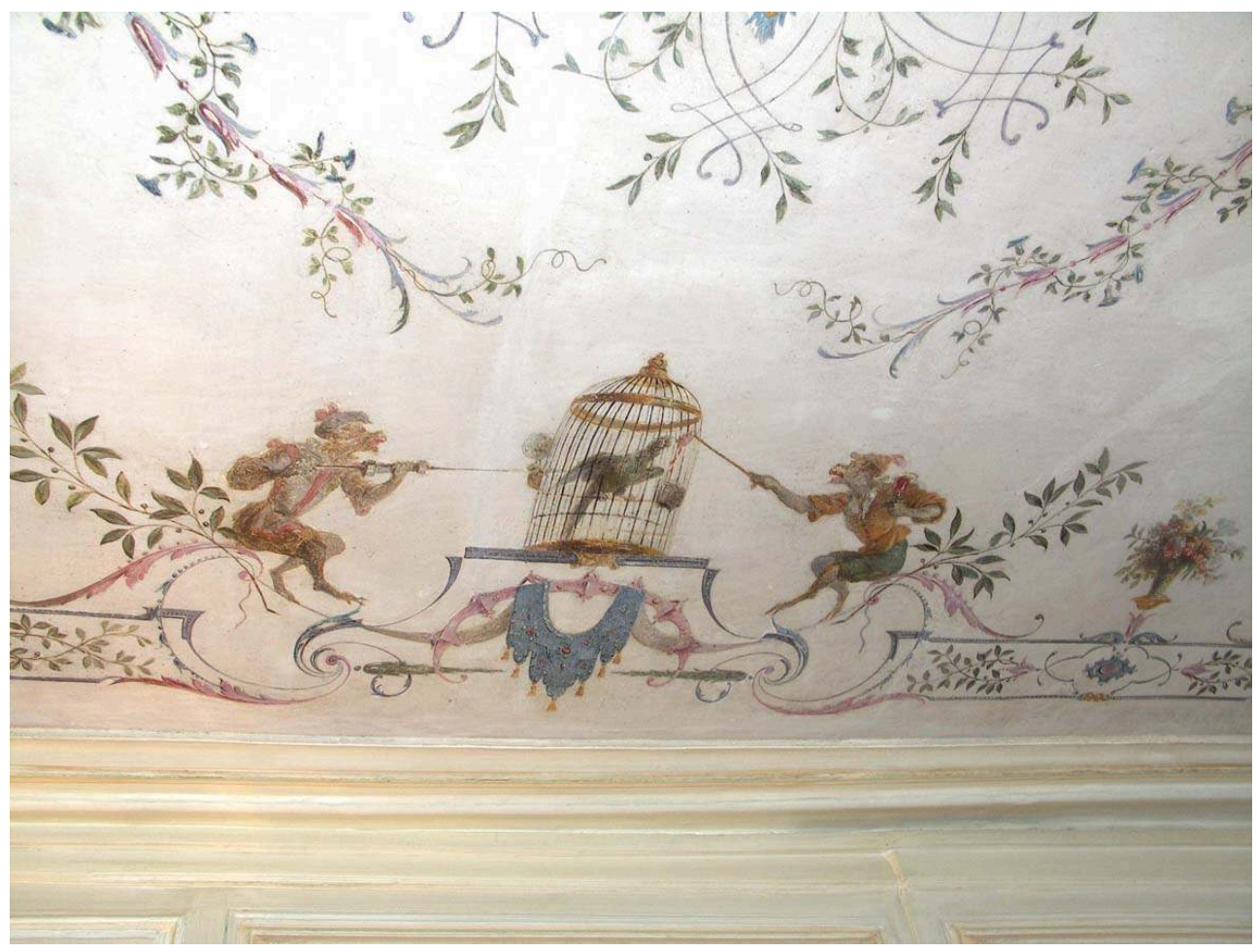

Plafond du cabinet. Singe à la seringue à lavement et singe au verre de vin rouge et au bâton, dont le bout est imprégné d'une éponge imbibée de vin.

Phot. Inizan, Christelle. (c) CRMH île-de-France, 2010. 
Les papillons de la folie (fig. $\mathbf{n}^{\circ} \mathbf{1 6}$ ), les couples de magots (fig. $\left.\mathbf{n}^{\circ} \mathbf{1 7}\right)\left(\right.$ (fig. $\left.\mathbf{n}^{\circ} \mathbf{1 8}\right)$, symboles de modestie et de sincérité - dont l'un présente toujours chapeau bas, appartiennent au riche et complexe bestiaire de la calotte (fig. $\mathbf{n}^{\circ} 19, \mathbf{n}^{\circ} \mathbf{2 0}, \mathbf{n}^{\circ} \mathbf{2 1}, \mathrm{n}^{\circ} \mathbf{2 2}$ et $\mathbf{n}^{\circ}$ 23). Manquent à l'appel les rats diffuseurs de brevets (dont on peut comprendre que le commanditaire n'ait pas voulu les voir courir sur son plafond!) et le lourd casque de plomb à deux oreilles d'où pendent grelots et sonnettes surmonté d'une girouette.

Figure 19

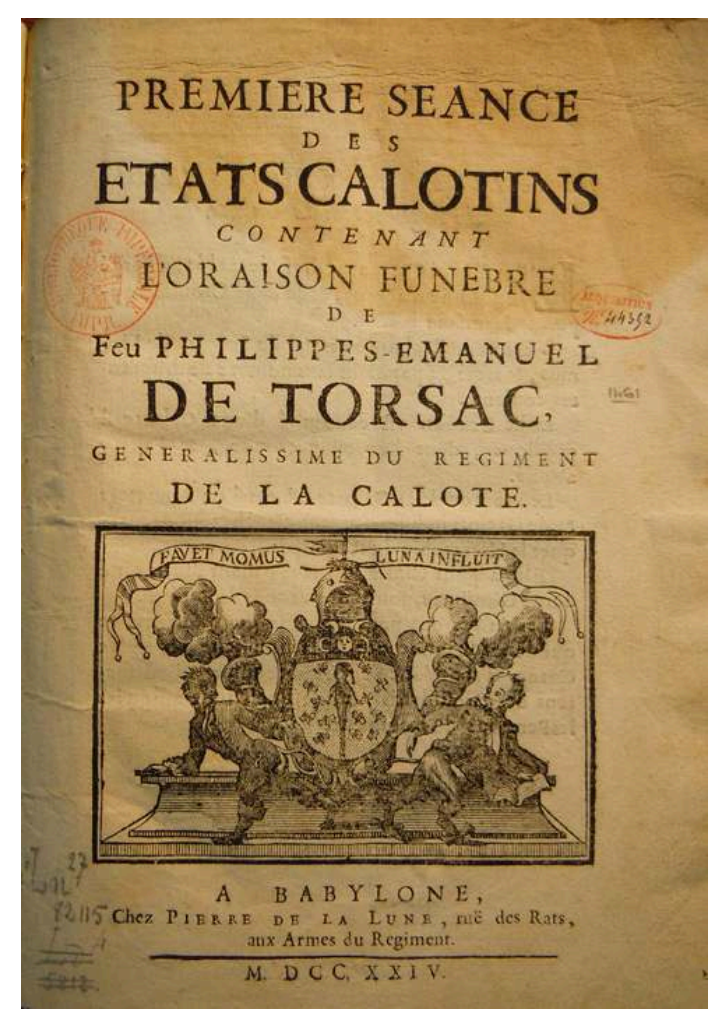

Frontispice. Guillaume PLANTIVIT de LA PAUSE. Étienne Isidore Théophile AYMON. Première séance des états calotins contenant l'oraison funèbre de feu Philippes-Emanuel de Torsac, généralissime du régiment de la calote. À Babylone, chez Pierre de la Lune, Maître des rats, aux armes du régiment, 1724. In $4^{\circ}, \mathrm{BnF}$ LN27- 82115.

(c) BnF. 
Figure 20

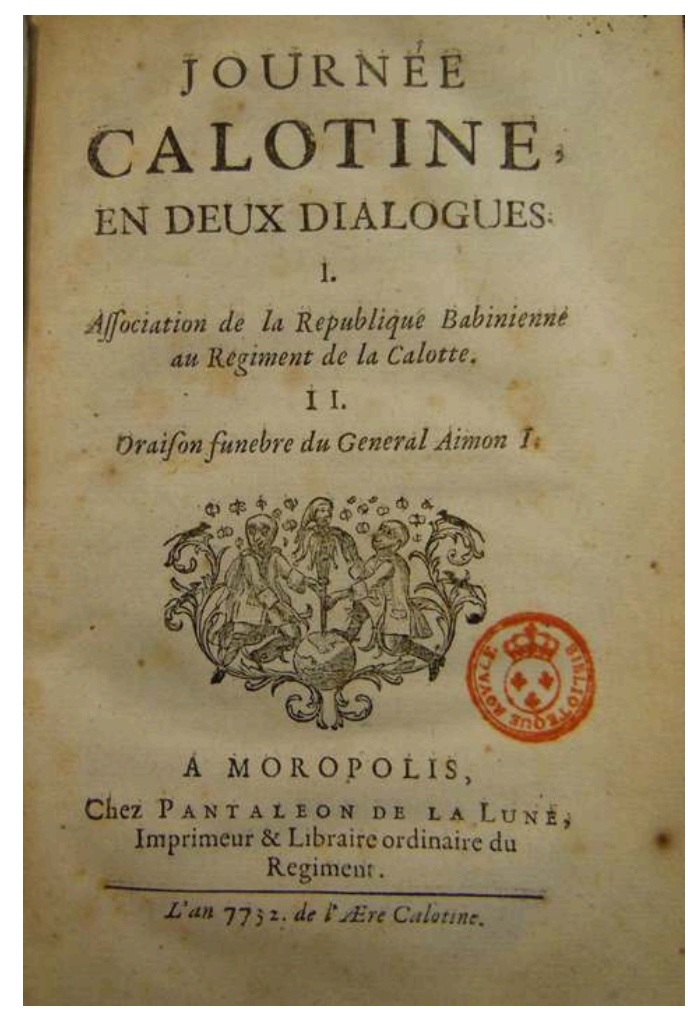

Frontispice. BOSC du BOUCHET. Journée calotine en deux dialogues. I. Association de la république babinienne au régiment de la calotte. II. Oraison funèbre du général Aimon Ier. À Moropolis, chez Pantaleon de la Lune, imprimeur et libraire ordinaire du régiment. L'an 7732 de l'ère calotine (1732). In $8^{\circ}, 121$ p., BnF Z 17183.

(C) BnF. 
Figure 21

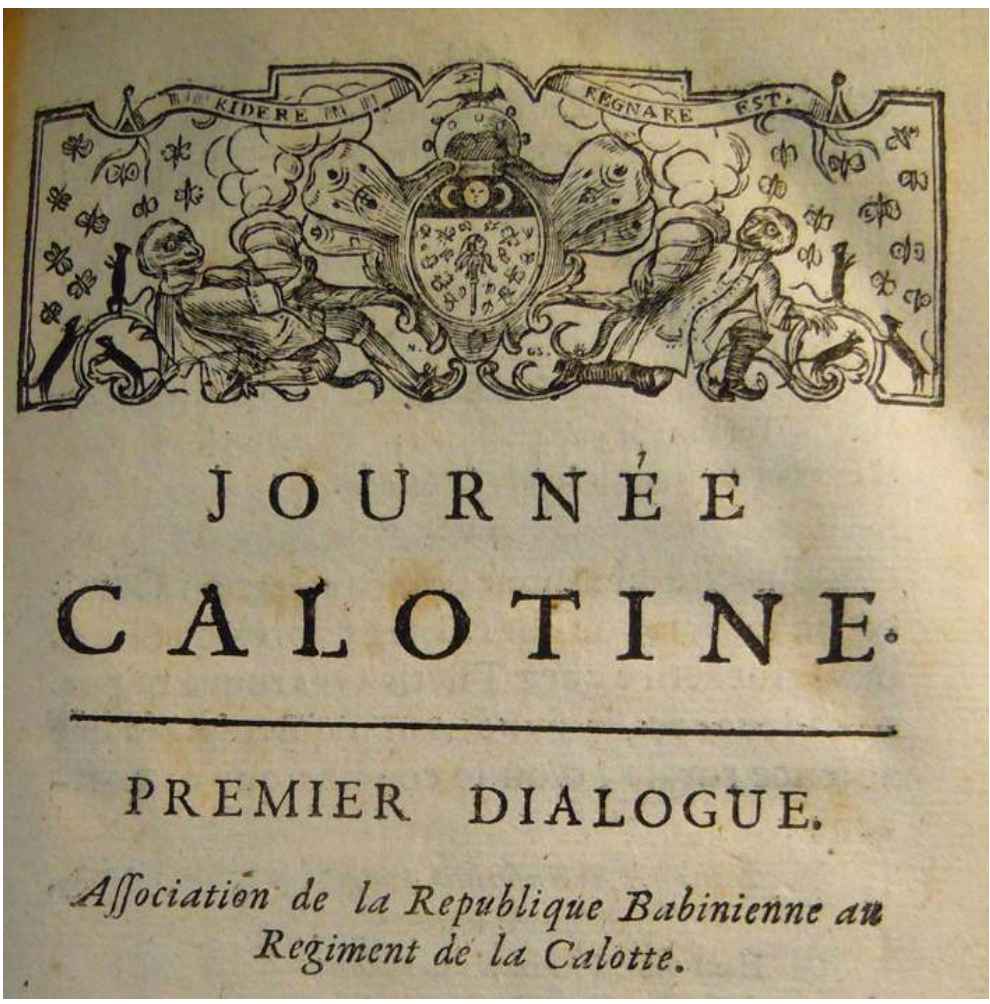

Haut de page du premier dialogue. BOSC du BOUCHET. Journée calotine en deux dialogues. I. Association de la république babinienne au régiment de la calotte. II. Oraison funèbre du général Aimon Ier. À Moropolis, chez Pantaleon de la Lune, imprimeur et libraire ordinaire du régiment. L'an 7732 de l'ère calotine (1732). In 8', 121 p., BnF Z 17183.

(C) BnF. 
Figure 22

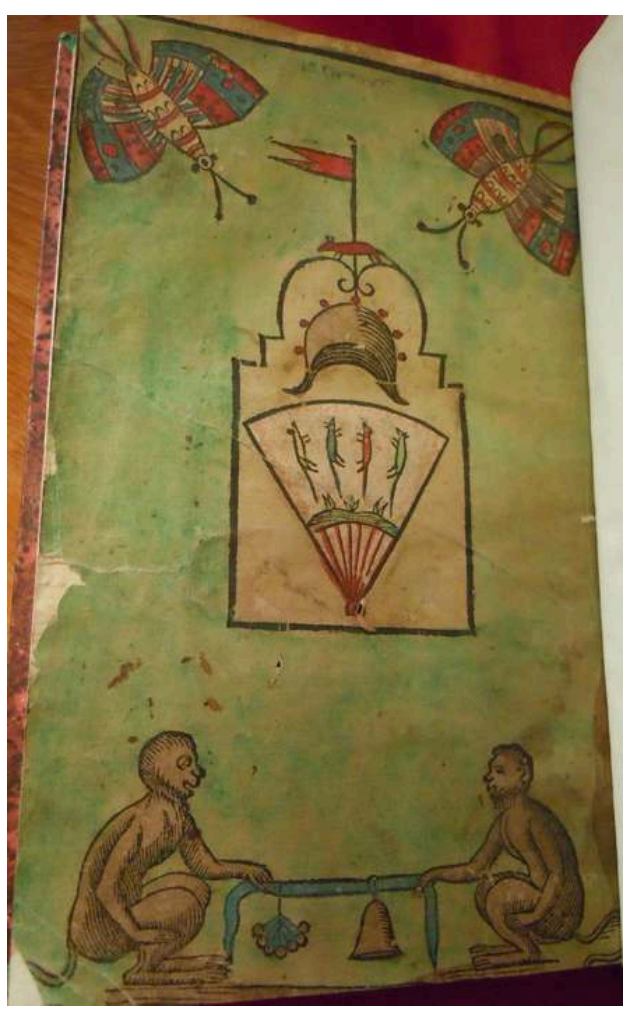

Feuille de garde imagée et aquarellée, recto. BOSC du BOUCHET. Journée calotine en deux dialogues. I. Association de la république babinienne au régiment de la calotte. II. Oraison funèbre du général Aimon Ier. À Moropolis, chez Pantaleon de la Lune, imprimeur et libraire ordinaire du régiment. L'an 7732 de l'ère calotine. BnF res Z 17183.

(C) BnF. 
Figure 23

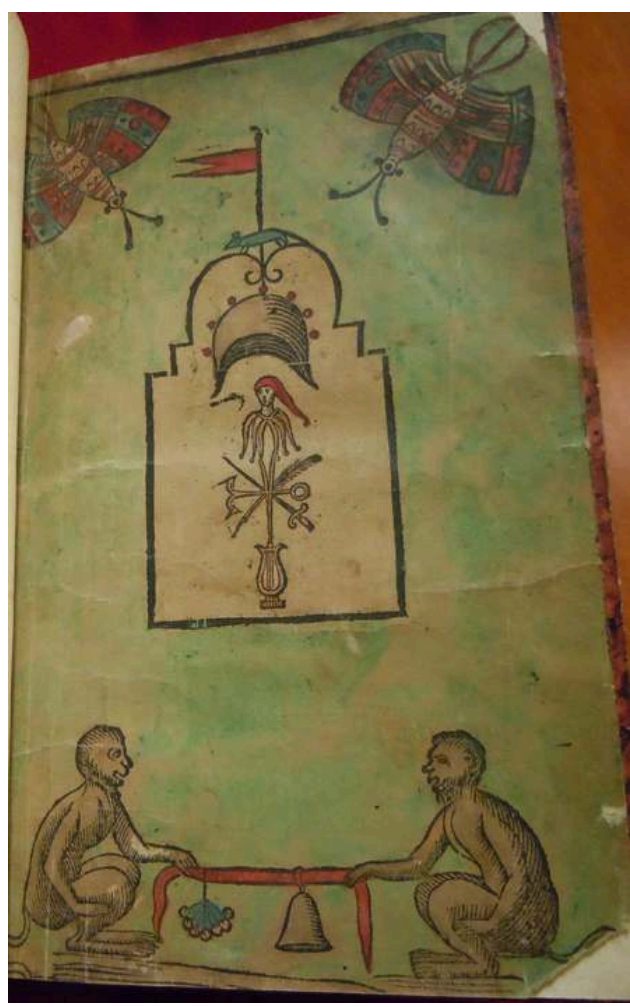

Feuille de garde imagée et aquarellée, verso. BOSC du BOUCHET. Journée calotine en deux dialogues. I. Association de la république babinienne au régiment de la calotte. II. Oraison funèbre du général Aimon $\left.\right|^{e r}$. À Moropolis, chez Pantaleon de la Lune, imprimeur et libraire ordinaire du régiment. L'an 7732 de l'ère calotine. BnF res Z 17183.

(c) BnF.

17 En revanche, le singe à la seringue à lavement paraît se référer aux pièces de Molière si prisées par les calottins ${ }^{23}$ ou encore à un épisode scandaleux relaté par les chroniques calottines $^{24}$ durant lequel Jean-César Rousseau de la Parisière, évêque de Nîmes, reçut d'une dame du Languedoc une seringue ridicule - allusion triviale à ses mœurs -.

18 Sur le plafond, les singes moriphiles - amis de la marotte - importunent des perroquets enfermés dans leurs cages dorées (sous-entendu évident aux antimômes - entendez ennemis de Momus -, esprits étriqués et bornés).

19 Mais les magots les plus intéressants sont ceux qui se font pendant (côté fenêtre et côté miroir), isolés dans leur médaillon respectif : le singe à la bulle de savon, dont la couche picturale est malheureusement très endommagée, et le singe à la lunette ou à la longue-vue.

\section{John Law : fieffé calottin !}

La lunette fait naturellement allusion à l'astre lunaire ${ }^{25}$ mais surtout à des événements historiques. L'existence d'une gravure à l'eau forte illustrant une planche de cartes à jouer néerlandaises de $1720^{26}$ (fig. $\mathbf{n}^{\circ} \mathbf{2 4}$ ) s'est révélée à cet égard fort précieuse à l'étude. Le jeu de cartes est placé conjointement sous les auspices de Momus et du célèbre financier écossais John Law. L'ensemble de la planche gravée se moque du régime de Law qui conduisit en 1720 à l'un des tout premiers krachs boursiers de 
l'histoire moderne connu sous le nom d'épisode de la bulle - spéculative - du Mississippi. On retrouve figurés sur cette planche le souffleur de bulles sur son rocher avec sa cruche remplie d'eau savonneuse et le savant astronome interrogeant les cieux à la lunette.

Figure 24

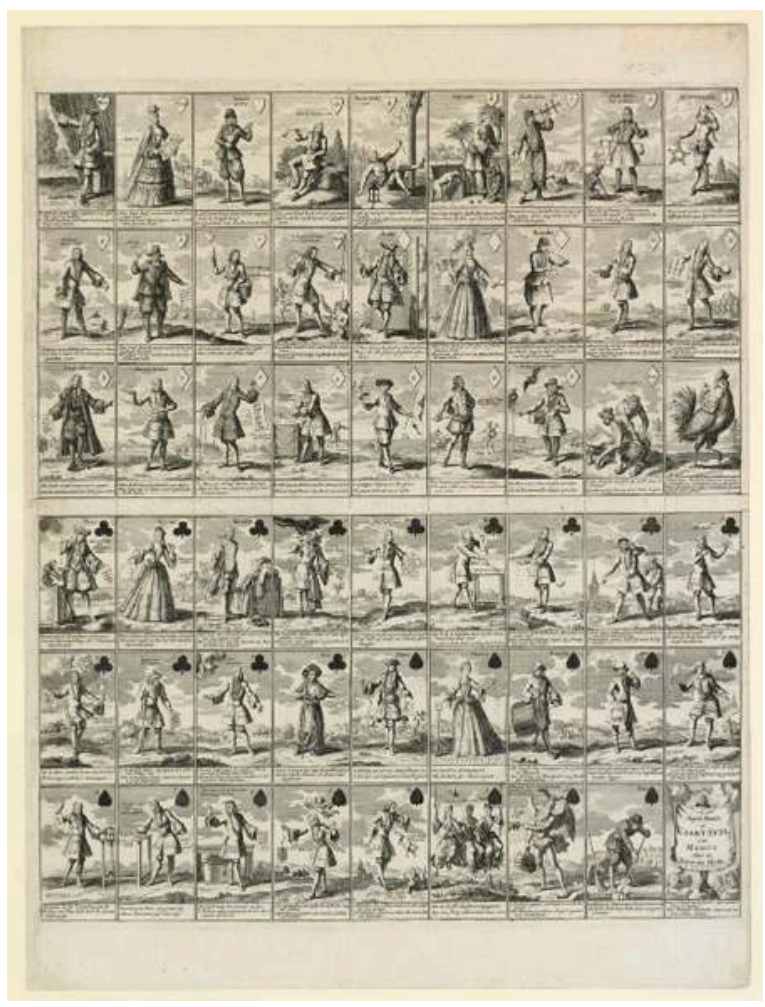

Gravure anonyme à l'eau-forte, 52,6 x 44,8 cm, planche de cartes à jouer "Cartes d'avril ou jeu de cartes de Momus à la dernière mode », Pays-Bas, s.d, v. 1720. BnF, Cabinet des estampes. RÉSERVE QB- 201 (170) -FT 4.

(C) BnF.

21 S'impose ici un court rappel des faits : dès les premiers temps de la Régence, dans une France endettée, Philippe d'Orléans s'intéresse aux propositions spéculatives de Law, lequel veut drainer les finances du royaume dans les caisses d'une banque privée qu'il compte fonder. Déjà, en juin 1707, Law avait adressé une lettre à Desmaretz, alors contrôleur des finances (et beau-frère de Louis Béchameil), pour lui exposer son idée de monnaie terrienne - les propriétaires, pour recevoir du numéraire, consigneraient leurs terres dans les mains du roi qui en percevrait les revenus et éteindrait ainsi les immenses dettes de la couronne -. L'affaire resta sans suite. En 1715, une nouvelle audience est accordée à l'écossais par Desmaretz. En 1716, la Banque Générale de Law est créée. En 1718, le Régent l'érige en Banque Royale. Elle a le droit d'émettre des billets au porteur en écus. Les affaires sont d'abord florissantes, la spéculation gonflant le cours des actions. Mais dès l'année suivante, les bénéfices se font attendre. Pour faire face, Law rachète pour quinze ans au financier Antoine Crozat le monopole du commerce et la pleine propriété des immenses réserves d'or situées en Amérique du Nord autour du fleuve Mississippi - Crozat accaparé à Saint-Malo par le commerce des Indes et de la Mer du Sud avait négligé cette fabuleuse concession de mise en valeur de la Louisiane qui d'évidence dépassait ses propres capacités de trésorerie -. Le financier 
Joseph Legendre d'Armeny, beau-père d'Antoine Crozat, intervint alors pour proposer d'étendre l'objet de cette nouvelle société au commerce des castors du Canada et à la traite des noirs de Guinée, rendue libre depuis un édit de janvier 1716. Il suggéra de l'appeler la Compagnie d'Occident ${ }^{27}$. Le nom fut retenu. Dès lors Law instaura l'émission d'une action populaire pour l'exploitation des mines. L'engouement fut extraordinaire. Mais la situation se dégrada plus rapidement que prévu pour aboutir à l'effondrement financier qui entraîna la ruine d'un dixième des français ${ }^{28}$.

Law, comme le relate un écrit calottin ${ }^{29}$, fut un temps recruté par les calottins " pour ses brillants systèmes financiers »:

Marchands, magistrats, artisans

Prélats, guerriers et courtisans,

Ducs et pairs, et même des princes

Non du pays, mais bien forains,

accouraient comme des essaims

Malgré le vent, grêle, pluie, crotte,

Pour y jouer à la marotte

En beaux et bons deniers comptant

Contre des valeurs calottines,

Dont la France et terres voisines

Se pourront souvenir longtemps. ${ }^{30}$

Mais comme l'explique Hennet dans son ouvrage, le régiment de la Calotte finit par se défaire des personnages qui cherchaient à assouvir leur avarice par des voies ambitieuses, Law en premier lieu ${ }^{31}$.

\section{Louis Béchameil de Nointel, moriphile zélé ?}

Le croisement d'indices comme la commande d'ouvrages de peinture à Audran citée dans l'inventaire après décès de Louis Béchameil, mort le 30 décembre 1718 à l'âge de 69 ans, et l'iconographie précise des singes à la bulle et à la lunette semblent accréditer l'hypothèse d'une datation $d u$ décor plafonnier comprise entre 1716-1718, correspondant à la période de pleine ascension de Law. Louis Béchameil n'a pas dû beaucoup profiter du décor! Certains esprits perspicaces s'étaient donc inquiétés fort tôt de cette dérive spéculative.

Mais qui était donc ce marquis de Nointel, amateur de chinoiseries et de singeries, collectionneur de porcelaines ${ }^{32}$ ? Un calottin assurément, même si son nom n'apparaît pas à proprement parler dans les brevets (la plupart du temps seules les initiales y figuraient) ni même dans les listes "officielles" des membres actifs du régiment établies au cours des premières décennies du XVIII ${ }^{e}$ siècle. Pour entrer dans ce cénacle de beaux esprits caustiques (Voltaire en fit un temps partie avant de s'en retirer après s'être fait moquer à son tour), il fallait se distinguer par sa singularité comique.

Autant son père, receveur général des finances de la généralité d'orléans, aurait pu avoir le profil pour être calottin, mais il est mort un an après la formation du régiment ${ }^{33}$, autant le fils ne semble pas s'être particulièrement distingué. Pourtant son appartenance au milieu financier (il appartenait au conseil du commerce au même titre que d'Aguesseau, breveté par les poètes calottins ${ }^{34}$ ), son lien avec l'armée (son frère et son fils étaient militaires) et le fait qu'il ait été affecté en 1709, à un poste d'inspecteur des vivres de l'armée (information trouvée dans les Mémoires de Saint-Simon) le désigne comme un candidat calottin de premier choix. 
27 Un curieux ouvrage de 1733 intitulé «Observations critiques sur le temple du Goût » rédigé par Jean du Castre d'Auvigny dénonce des travers calottins qui pourraient bien être ceux de Louis Béchameil, ce "Crésus entouré de faux connaisseurs, de peintres, d'architectes, de sculpteurs et de doreurs ${ }^{35}$. Voltaire débite alors une tirade de vers burlesques dans le goût du "Virgile travesti », et voici ce qu'il met dans la bouche d'un maçon : "Vous n'aurez dans votre palais, dit-il au Crésus, nul vestibule, encore moins de façade; vos murs seront de deux doigts d'épaisseur; grands cabinets, salons sans profondeurs ». Un peintre interrompt ce Vitruve pour dire une autre impertinence: «Je couvrirai plafonds, voûtes, voussures; par cent magots travaillés avec soin, d'un pouce ou deux pour être vus de loin ». Ce n'est pas tout, un faux connaisseur succède à ce peintre et conseille au richard d'acheter un tableau : «C'est Dieu le Père, en la Gloire éternelle, peint galamment dans le goût du vatau »».

Si l'on ne peut mettre un nom sur le personnage brocardé, il n'en demeure pas moins que ce texte colle parfaitement à l'esprit du temps.

\section{Un décor Régence exceptionnellement préservé}

Ce plafond peint est un décor unique qui fait référence à une page peu connue de l'histoire de France. Le Régiment de la calotte se trouve en effet au centre d'une querelle des lettres et au cœur des tensions politiques de cette première moitié du XVIII ${ }^{e}$ siècle. Jusqu'ici, seules des publications (semi-clandestines) et des médailles, des commentaires d'opposants à la Calotte aussi, attestaient de son existence qui s'est achevée en 1752, lorsque Louis XV exigea sa dissolution, suite à la diffusion des " poissonnades » à l'encontre de la marquise de Pompadour.

Cette réalisation picturale, mise en perspective avec les allusions certaines au théâtre de foire du plafond du 26 rue de Condé, rend le sujet passionnant. Preuve qu'Audran, entrepreneur décorateur en vogue, et Watteau, créateur de mythologie théâtrale, s'adaptaient aux désirs des commanditaires, jusqu'à choisir des thèmes iconographiques antinomiques, tout en restant dans le goût à la mode de la singerie. Les calottins, farouches partisans du rire nobiliaire, caractérisé par un certain entresoi, ne luttaient-ils pas précisément contre l'esprit frondeur, populaire, des comédiens italiens?

Les deux plafonds sont donc les témoins décoratifs précieux, opposés mais complémentaires, de cette pensée contestataire de la Régence.

Peut-être le passage de Beaumarchais rue de Condé est-il à l'origine de la préservation respectueuse du plafond. Mais qu'est-ce qui a sauvé partiellement le décor du cabinet de Nointel ? La petitesse de la pièce et son retrait par rapport aux grands salons et aux circulations de l'hôtel ? La drôlerie de ses thèmes simiesques, qui transcende les modes - ce malgré la perte progressive du sens obvie de la thématique calottine du plafond - ? Il est vrai que l'attrait esthétique subsiste, la fraîcheur des couleurs (sur fond blanc) rappelant la porcelaine peinte.

33 Chez Watteau, le rire parait toujours sous contrôle, domestiqué. En répondant aux desiderata de la clientèle calottine, il semble s'être laissé porter par un humour plus léger, sans s'affranchir pour autant de l'obligation de se tenir au plus près de la codification symbolique du régiment. Les apports d'Audran à la peinture de Watteau sont connus : le thème de la singerie, le végétal ornemental, la distribution spatiale de 
l'ornement. Tout cela est clairement perceptible sur ce plafond de l'hôtel de Nointel, modeste en taille mais combien précieux pour la rareté de son iconographie.

Bien des interrogations subsistent encore, en particulier sur l'écheveau des réseaux d'influence des deux peintres, sur la nature des relations entretenues entre ces artistes et leurs commanditaires appartenant souvent à la noblesse affairiste du début du XVIII ${ }^{\mathrm{e}}$ siècle : les Crozat, Legendre d'Armeny et Nointel. À l'aune de cette lecture calottine, une autre histoire reste à écrire.

\section{NOTES}

1. - Mes remerciements vont à : M. Jean Bégon-Lours, Président directeur général de la Maison des Polytechniciens, ainsi qu'à Mmes Corinne Fortin et Barbara Laux.

2. - Béchameil de Nointel (Louis) 1649-1718. Petit-fils d'un libraire de Rouen, Jean Béchameil. Fils de Marie Colbert, fille de Nicolas, et de Louis Béchameil de Nointel (v. 1630-1703), financier, gastronome et homme d'esprit - que Louis XIV, qui le traitoit bien, consultait souvent sur ses bâtiments et sur ses jardins et le menoit quelquefois à Marly. Sans Mansart, qui en prit beaucoup d'inquiétude, le Roi lui auroit marqué plus de confiance et de bonté-. Mémoires de Saint-Simon (1703): nouvelle édition collationnée sur le manuscrit autographe, augmentée des additions de Saint-Simon au Journal de Dangeau. Tome XI, notes et appendices par Arthur-Michel de Boislisle. Paris : éd. Hachette, 1879-1928, p. 96-97. Frère d'un lieutenant aux gardes; de Marguerite, épouse du contrôleur général des finances Nicolas Desmarest; de Marie-Louise, épouse du comte de Cossé. Époux de Marguerite Hyacinthe Le Ragois de Bretonvilliers, que Madame de Sévigné traitait de haut. D'abord substitut du procureur général au parlement de Paris en 1669, puis conseiller, et député pour la vérification des actes de la chambre des comptes de Nantes, il fut nommé intendant à Tours en1680 et fit élever dans cette même ville un arc de triomphe à la gloire de Louis XIV, détruit en 1777. Nointel fut transféré à Chalons en 1689, en Bretagne en 1691. Nommé conseiller d'État en 1700. PRÉVOST, ROMAN D'AMAT. Dictionnaire de biographie française. Paris : éd. Librairie Letouzy et Ané, 1949, fascicule XXV, p. 1235-1236. Nointel fut encore missionné par le Régent le 4 janvier 1716 comme conseiller au conseil du commerce. Lui revint la gestion « de toutes les affaires commerciales intéressant les manufactures des provinces de Bretagne, Touraine, Maine, Anjou, Champagne, Brie et Sédan, Poitou, Saintonge, d'Aunis, Berri, Bourdonnais et de la généralité d'Orléans ; les pêches de la morue et du hareng, de la baleine et autres et le commerce du poisson de mer, le commerce des colonies îles françaises et autres pays de l'Amérique de la domination du roi ». ISAMBERT, DECRUSY, TAILANDIER. Recueil général des anciennes lois françaises. Paris : éd. Belin-Leprieur, 1830, tome XXI - 1715-1737, p. 74-75.

3. - À qui fut passée la commande d'ouvrages de peinture comme l'atteste la pièce comptable $n^{\circ} 59$ récolée dans le volumineux inventaire après décès du conseiller d'état ordinaire Louis Béchameil daté du 8 mars 1719. «Une liasse de quatre pièces qui sont recouvrement et quittance $\mathrm{du}$ sieur Audran, peintre, pour ouvrage fait cy la dite maison ». Archives Nationales, Minutier Central des notaires, étude XXXIX, carton 300.

4. - EIDELBERG, Martin. Watteau and Audran at the Hôtel de Nointel. Apollo, The International magazine of the arts. London, janvier 2002, p. 10-16.

5. - Contredisant l'affirmation de Jean Cailleux, reprise dans l'ouvrage de Guillaume Glorieux, selon laquelle les huit panneaux de l'hôtel de Nointel, peints vers 1707-1708, se trouvaient sur 
deux niveaux différents. CAILLEUX, Jean. «Decorations by Antoine Watteau for the Hotel de Nointel». The Burlington Magazine. London, $n^{\circ} 696$, supplément $n^{\circ} 7$, mars 1961. GLORIEUX, Guillaume. À l'enseigne de Gersaint. Paris : éd. Champ Vallon, 2002, p. 202-204, 209-210.

6. - Les eaux-fortes sur papier vergé gravées par Pierre AVELINE le vieux (vers 1656-1722) sont consultables: Bacchus (1738)-BnF - Db.15h.rés in-folio et bibliothèque de l'UCAD, collection Maciet, série Graveurs et ornemanistes- ; le faune (1738)-BnF - Db.15a in-folio et Hd.79 in-folio, p. 46, ainsi qu'au musée de Valenciennes- ; le buveur (1738)-BnF - Db.15a in-folio et Hd.79 in-folio, p. 48, ainsi qu'au musée de Valenciennes-; l'enjôleur (1731)-BnF - Db.15h.rés in-folio et bibliothèque de l'UCAD, collection Maciet, série Graveurs et ornemanistes- Celles de Jean MOYREAU (1690-1762) sont également consultables: Momus (1738)-BnF Richelieu-musique VMPHOT MIRI-18 (455) et BnF Hd.79, p. 47 ; la Folie (1738)-BnF - Hd.79 in-folio, p. 45 et bibliothèque de l'UCAD, collection Maciet, série Graveurs et ornemanistes, ainsi qu'au musée de Valenciennes; le vendangeur (1731)-bibliothèque de l'UCAD, collection Maciet, série Graveurs et ornemanistes-; le frileux (1731)-bibliothèque de l'UCAD, collection Maciet, série Graveurs et ornemanistes-.

7. - Guillaume Glorieux indique dans son ouvrage consacré à Gersaint, que des séries gravées d'après Watteau mises en vente par Gersaint, pouvaient servir aux fabricants de paravents. Ce fut semble-t-il le cas pour les quatre gravures illustrant Momus, le buveur, la Folie, le faune. Le Mercure de France, en juin 1738 (p.1165), annonce la vente de ces "quatre morceaux d'ornements en hauteur comme des paravents, très ingénieusement composés». GLORIEUX, Guillaume. À l'enseigne de Gersaint. Paris : éd. Champ Vallon, 2002, p. 195, 197, 214.

8. - Le petit panneau décoratif $(25 \times 36 \mathrm{~cm})$ sur fond blanc, à motif de couronne de fleurs traversée par deux thyrses en sautoir, mis en vente en 1885, en même temps que les panneaux de L'enjôleur et du faune, appartenait-il à cet ensemble? Edmond de Goncourt avait signalé l'existence de ces trois panneaux dix ans avant leur dispersion en salle des ventes. GONCOURT (de), Edmond. Catalogue raisonné de l'Euvre peint, dessiné et gravé d'Antoine Watteau. Paris: éd. Rapilly, 1875, p. 206-208.

9. - Disposition proposée par Michel Borjon en 1987 dans son article sur l'hôtel de Nointel. BORJON, Michel. « Hôtel Béchameil de Nointel - Hôtel Chauvelin - Hôtel du Poulpry - Maison des Polytechniciens ». Le faubourg Saint-Germain: rue de l'Université. Catalogue d'exposition sous la direction de MAGNY Françoise. Institut néerlandais. Paris : Délégation à l'Action Artistique de la Ville de Paris et Société d'histoire et d'archéologie du VII ${ }^{\mathrm{e}}$ arrondissement, 1987, p. 184-197.

10. - Se reporter à l'ouvrage de TOMLINSON, Robert. Watteau et Marivaux : la fête galante. GenèveParis : Librairie Droz, 1981.

11. - Même agencement du buste de Momus dans le tableau de Voulez-vous triompher des belles? huile sur panneau d'Antoine Watteau, vers 1714-1717, 35,9 x $27 \mathrm{~cm}$, conservé à la Wallace Collection à Londres. Gravure reprenant cette œuvre par Thomassin, dédiée au comte de Caylus, datée de l'année 1725. Autres variations : Sous un habit de Mezzetin, huile sur panneau 27,1 x $19 \mathrm{~cm}$, vers 1717-1719, peint par Watteau, lui aussi conservé à la Wallace Collection à Londres ; Les comédiens italiens, huile sur toile 63,8 x 76,2 cm, vers 1720 , conservé à la National Gallery of Arts à Washington (où l'on retrouve le fou à la marotte en bas à gauche et Momus en mascaron, audessus du Pierrot présidant une fois de plus l'ensemble de la composition).

12. - Commentaire et illustrations dans l'ouvrage de TOMLINSON, Robert. Watteau et Marivaux : la fête galante. Genève-Paris : Librairie Droz, 1981, ill. 20, 21, p. 92-93, 97. Lire également REGNARD. Le mariage de la Folie. Réédité dans Oeuvres complètes. Paris : éd. Didot aîné, 1823, tome II, et DANCOURT, Florent. L'impromptu de Suresnes, qui fut joué par la Comédie Française devant l'Électeur de Bavière (il s'agissait d'une comédie illustrant la rencontre de la Folie et de Bacchus). 13. - Edme-François Gersaint ne jugeait-il pas son ami Watteau «libertin d'esprit mais sage de mœurs"? Biographie d'Antoine Watteau publiée par E.F. Gersaint dans le catalogue de vente Quentin de Lorangère «Catalogue raisonné des diverses curiosités du cabinet de feu M. Quentin 
de Lorangère ». Paris, 1744 (1), p. 187. Biographie augmentée de la réponse à une critique anonyme dans le catalogue de la vente Angran de Fonspertuis en 1747.

14. - Jean Moyreau grava les deux compositions en 1729. Ces eaux-fortes sur papier vergé $(35,6 \mathrm{x}$ 42,8 ) sont aujourd'hui consultables au Cabinet des Estampes de la Bibliothèque nationale de France et à la bibliothèque de l'Union Centrale des Arts Décoratifs à Paris. Les enfants de Momus (BnF - EE 13 fol. et Hd.79 in-folio, p. 25) et La Cause Badine (BnF - Hd.79 in-folio, p. 24 et bibliothèque de l'UCAD, collection Maciet, série Décoration « Recueil de gravures en tous genres la pluspart d'après Watteau »). Un premier état de La Cause Badine se trouve également conservé à Valenciennes, au musée des Beaux-Arts.

15. - DINAUX, Arthur. Les sociétés badines, bachiques, chantantes et littéraires. Paris, 1867, p. 134-142. HENNET, Léon. Le régiment de la Calotte. Paris : Librairie des bibliophiles, 1886.

16. - BAECQUE (de), Antoine. Les éclats du rire. Le Régiment de la calotte ou les stratégies aristocratiques de la gaieté française (1702-1752). Paris : Annales HSS, mai-juin 1997, n³, p. 477-511. www.persee.fr/ web/.../ahess_0395-2649_1997_num_52_3_279581. BAECQUE (de), Antoine. Les éclats du rire. La culture des rieurs au XVIII ${ }^{e}$ siècle. Paris : éd. Calmann-Lévy, 2000.

17. - Oraison funèbre du général Aimon 1er. Paris, 1732. BnF Z 17183 Bis, p. 2-4 et BnF Z 17183.

18. - Au sénat, pinte de vin est nécessaire.

Pour traiter une grande affaire.

Quant tout le monde en avait bu.

C'est icy le coup de partance.

Brevet cité par Antoine de Baecque, op.cit., p. 39.

19. - Une médaille du régiment de la calotte, conservée au cabinet des médailles de la BnF, présente à l'avers Momus trônant au-dessus d'un tapis de nuages qui agite sa marotte. RIDERE REGNARE EST : Rire c'est régner ! Au revers, les armes du régiment : la calotte à grelots avec pour cimier un rat; le blason: une marotte sur fond de papillons surmontée d'une lune entourée de deux croissants. Deux cornes d'abondance inversées d'où sortent de la fumée et des vents. Deux singes flanquent l'ensemble: celui portant l'épée tient en main son chapeau (attitude quasi identique sur le plafond de l'hôtel de Nointel); l'autre tient un brevet satirique. LUNA DUCE AUSPICE MOMO : Avec la lune pour guide et sous les auspices de Momus.

20. - Le drapeau du Régiment de la calotte inventé par le général, dessiné par Coypel (signé Ch. $\left.\mathrm{C}^{* *}\right)$ édité par Surugue illustre la page 229 de l'ouvrage de Léon HENNET. Le régiment de la Calotte. Paris : Librairie des bibliophiles, 1886.

21. - C'est assez. Votre affaire est juste

Calottins, écoutez Momus :

Que cet avocat soit trompette

Dans la brigade des cocus.

Brevet d'enregistrement à la calotte envoyé à un avocat ridiculisé par ses infortunes conjugales. DINAUX, Arthur. Les sociétés badines, bachiques, chantantes et littéraires. Paris, 1867, p. 140.

22. - Le blason du régiment en appelle à la légitimité nobiliaire en se plaçant sous la double épée des mousquetaires du roi.

23. - Lire la pièce de théâtre Le Régiment de la calotte représentée par l'Opéra Comique à la Foire Saint-Laurent le 1er septembre 1721, puis au Palais Royal le 2 octobre suivant. Cette farce satirique se concluait par une procession calquée sur la cérémonie du Bourgeois Gentilhomme de Molière. LESAGE, Alain René, ORNEVAL (d'). Le Régiment de la calotte (pièce en un acte). Théâtre de la foire ou l'Opéra-Comique. Éd. Ganeau, 1724, tome V, p. 1-46.

24. - HENNET, Léon. Le régiment de la Calotte. Paris : Librairie des bibliophiles, 1886, p. 58.

25. - HENNET, Léon. Le régiment de la Calotte. Paris : Librairie des bibliophiles, 1886, p. 2, p. 12

26. - Gravure à l'eau forte, 52,6 x 44,8 cm, «April-Kaart of Kaart Spel van Momus naar de Nieuwste Mode» (Cartes d'avril ou jeu de cartes de Momus à la dernière mode), anonyme, s.d. (vers 1720), conservée à la BnF au cabinet des estampes - RÉSERVE QB- $201(170,8)$ - FT 4. 
27. - Joseph Legendre d'Armény est le commanditaire du plafond parisien du 26 rue de Condé peint par Audran, Watteau et Lancret. Deux des singes du décor faisaient explicitement allusion à l'île de Saint-Domingue et au commerce triangulaire. INIZAN, Christelle. "Découverte à Paris d'un plafond peint à décors de singeries attribué à Claude III Audran, Antoine Watteau et Nicolas Lancret » [document électronique]. In situ, revue des patrimoines, 2011, $\mathrm{n}^{\circ} 16$. Un neveu de Claude III Audran, Gabriel Audran, se trouvait lui aussi aux îles de Saint-Domingue (inventaire après décès de Claude III Audran AN/MC/ET/XLIX/553).

28. - Lire PETITFILS, Jean-Christian. Le Régent. Paris : éd. Fayard, 1996, p. 349, 372-380.

29. - Mémoire pour servir à l'histoire de la calotte. Nouvelle édition augmentée d'une $3 \mathrm{e}$ et $4 \mathrm{e}$ parties à Moropolis chez le libraire de Momus à l'enseigne du jésuite démasqué, 1735, p. 22 (Brevet de contrôleur général des finances pour le sieur Law « qui nous a donné maints calottins »); p. 53-55 (Brevet accordé au sieur Bassin - notaire de John Law - qui a gagné plusieurs millions «Fixons 2000 écus de tournois, à recevoir sur la fumée, et vapeur qui s'exhalera, des billets que l'on brûlera ») ; p. 188-192 (Lettre du Général de la calotte, doyen de la Faculté le 26 juillet 1722. Sur l'air de Joconde « C'est Law qui gouverne aujourd'hui, l'État et la Finance, les espagnols d'Alberoni, redoutent sa puissance, tout serait au même niveau, si la cour germanique, nous faisait voir encore Rousseau, chef du conseil aulique ». BnF RÉSERVE Z 2428.

30. - DINAUX, Arthur. Les sociétés badines, bachiques, chantantes et littéraires. Paris, 1867, p. 135.

31. - HENNET, Léon. Le régiment de la Calotte. Paris : Librairie des bibliophiles, 1886, p. 43.

32. - Lire inventaire après décès de Nointel du 8 mars 1719. Archives nationales, Minutier Central des notaires, étude XXXIX, carton 300.

33. - Son nom est resté dans l'histoire gastronomique du fait de la création de la sauce éponyme et aussi dans les différentes chroniques de la fin du règne de Louis XIV. Par exemple dans le Journal du marquis d'Argenson et dans les Mémoires du duc de Saint-Simon (rééditées par Boislisle) qui relate la raillerie du comte de Fiesque dont Béchameil père fut la victime (tome XVI, p. 419) et l'épisode du coup de pied au c. du duc de Grammont (tome XI, p. 94-97).

34. - DINAUX, Arthur. Les sociétés badines, bachiques, chantantes et littéraires. Paris, 1867, p. 141.

35. - CASTRE d'AUVIGNY (du), Jean. Observations critiques sur le temple du goût. Paris, 1733.

\section{RÉSUMÉS}

La Maison des Polytechniciens - ancien hôtel de Nointel - sert actuellement de lieu de réception de prestige à Paris. Bien que ses décors du XVIII ${ }^{\mathrm{e}}$ siècle aient été passablement transformés ou pastichés au XIX siècle, ce bâtiment recèle encore un décor authentique, un plafond à décor de singeries peint par Antoine Watteau et Claude III Audran qui orne un petit cabinet situé au premier étage du corps de logis principal, situé en fond de cour. Une étude récemment entreprise a conduit à reconsidérer l'ornementation de cette pièce dans son ensemble. L'essai de reconstitution de la disposition murale des panneaux réalisés par Watteau et sa confrontation avec le décor plafonnier existant a permis l'identification de l'iconographie générale du cabinet : les symboles du Régiment de la Calotte, surtout connus des bibliophiles et des historiens et dont on pouvait penser qu'ils n'appartenaient qu'au domaine de l'édition.

House of Polytechnicians - ancient Hotel of Nointel - currently serves as a prestigous reception venue in Paris. Although these decorations of the eighteenth century were quite transformed or pastiched in the nineteenth century, the building still has an authentic decor, with a ceiling 
decor of decorated monkeys painted by Antoine Watteau and Claude Audran III adorning a small room on the first floor of the main residence, located in the courtyard. A recent study led to a reconsideration of the ornamentation of the room as a whole. The attempt to reconstruct the layout of the wall panels made by Watteau and his confrontation with the existing ceiling allowed the identification of the room's overall iconography: symbols of the Regiment de la Calotte, known especially to book lovers and historians, wich can be assumed to have belonged only to the world of publishing.

\section{INDEX}

Mots-clés : Nointel, Watteau, Audran, John Law, Momus, Bacchus, Régiment de la Calotte, mousquetaires, singerie, art décoratif, plafond, XVIIIe siècle, Régence, Paris, Maison des Polytechniciens

Keywords : ornemental art, ceiling, monkeys, eighteenth century, regency

\section{AUTEUR}

\section{CHRISTELLE INIZAN}

Chargée d'études et de recherches, Médiathèque de l'Architecture et du Patrimoine, Centre de recherches sur les Monuments historiques christelle.inizan@culture.gouv.fr 